\title{
Desafíos para la protección de las personas mayores y sus derechos frente a la pandemia de COVID-19
}

\section{Introducción ${ }^{1}$}

La crisis sanitaria y económica, sin precedentes en los últimos 100 años, que sobrevino con el surgimiento del nuevo coronavirus y la enfermedad de COVID-19 ha puesto las desigualdades socioeconómicas y de acceso a los servicios de salud y protección social aún más en evidencia, además de plantear desafíos socioeconómicos y exponer a los grupos más vulnerables de la población a riesgos y adversidades más graves de los que ya enfrentaban.

Entre los grupos más vulnerables, que sufren consecuencias directas de la pandemia en su calidad de vida y enfrentan desafíos respecto del cumplimiento de sus derechos, están las personas mayores. Las evidencias científicas sobre la evolución de la pandemia y los factores de riesgo vinculados al COVID-19 han mostrado que las personas de todas las edades corren riesgo de contraer la enfermedad por el SARS-CoV-2. Sin embargo, las personas mayores, en particular las de 80 años y más, tienen más probabilidades de presentar síntomas graves, un agravamiento del cuadro clínico y morir (OMS, 2020a; Naciones Unidas, 2020b). Los estudios también han dejado claro que la preexistencia de enfermedades crónicas y degenerativas constituye otro factor de riesgo asociado a la probabilidad de agravamiento y mortalidad por COVID-19 (OMS, 2020a), y es bien sabido que estas comorbilidades son más frecuentes entre las personas mayores.

De ahí la importancia de la protección de los derechos de las personas mayores en este contexto de crisis sanitaria, que deben desplegarse en dos ámbitos: por una parte, el derecho a la salud, que debe ser para todos, sin discriminación por edad, y, por la otra, el derecho a la vida y el derecho a vivir con dignidad en la vejez.

Con relación a la estructura etaria, el proceso de envejecimiento poblacional de los países de América Latina y el Caribe es heterogéneo, y muestra avances e intensidades diferentes. El proceso de envejecimiento en la región aún está lejos del observado en Europa y en países desarrollados, donde la estructura etaria envejecida y el patrón de contagios concentrado en este grupo fueron decisivos para la alta mortalidad registrada en un período corto de tiempo. De hecho, aunque la estructura etaria de la región tiende a envejecer, actualmente el $13 \%$ de la población son personas de 60 años y más, cifra muy inferior al $25 \%$ o más de varios países europeos. Además, la región presenta una diversidad de situaciones, con países en etapas avanzadas o muy avanzadas del proceso, y otros que aún se encuentran en una trayectoria incipiente de envejecimiento (Naciones Unidas, 2019a).

Entretanto, los países con menor porcentaje de personas mayores son, en general, los más rezagados en materia de desarrollo social y económico, y exhiben riesgos estructurales graves. Estos países suelen dedicar menos recursos a la atención sanitaria, tienen sistemas de salud que aún se encuentran en etapa de organización, disponen de experiencia limitada
Introducción

A. Vulnerabilidades sociodemográficas de las personas mayores frente al COVID-19

B. Acciones nacionales y locales específicas dirigidas a las personas mayores

C. Recomendaciones para la orientación de políticas

Bibliografía

La información empleada para la elaboración de este documento, salvo que se indique otra cosa, es la disponible hasta el 31 de agosto de 2020.

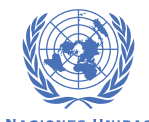

CEP A L
COVID-19 RESPUESTA 
en la asistencia y el cuidado de personas mayores, y cuentan con sistemas de protección y seguridad social con baja cobertura y acceso desigual.

Además, se ha observado que el riesgo de infección de las personas mayores se ve aumentado por otros factores resultantes de las interacciones entre los factores demográficos y socioeconómicos. Entre ellos se cuentan: el alto grado de hacinamiento en los hogares, la corresidencia intergeneracional, la falta de acceso a sistemas de agua y saneamiento adecuados, y el alto grado de concentración de población en áreas urbanas con grandes déficits en materia de vivienda y servicios básicos.

Respecto de este último factor, cabe aclarar que América Latina y el Caribe es la región más urbanizada del mundo en desarrollo, ya que más del $81 \%$ de las personas viven en áreas urbanas (Naciones Unidas, 2019a, 2019b, 2019c y 2019d). La urbanización está muy concentrada en ciudades grandes (metrópolis con un millón de habitantes o más, y megalópolis con 10 millones de habitantes o más) que, en general, presentan una gran segregación residencial y desigualdad social, lo que constituye un factor de riesgo para el rápido contagio del COVID-19 (Naciones Unidas, 2020b). Si bien, de acuerdo con la Organización Mundial de la Salud (OMS, 2020e), la concentración de la población en las grandes ciudades puede posibilitar un mejor acceso a los cuidados de salud y las grandes ciudades están más preparadas para aumentar con rapidez la capacidad de sus sistemas de salud, también ocurre que estas eventuales ventajas en parte se neutralizan por los déficits y las desigualdades que caracterizan a las ciudades de la región.

Las desigualdades sociodemográficas, económicas y en los determinantes de la salud se acumulan, se potencian e interactúan entre sí, causando múltiples discriminaciones que conllevan diferencias en el ejercicio de los derechos (CEPAL, 2020b). Los efectos nocivos de la pandemia en las condiciones de vida de las personas mayores son evidentes. De allí la necesidad de que la protección de sus derechos esté en el centro de los esfuerzos de respuesta, al amparo de instrumentos y acuerdos internacionales como el Plan de Acción Internacional de Madrid sobre el Envejecimiento (Naciones Unidas, 2003), la Carta de San José sobre los Derechos de las Personas Mayores de América Latina y el Caribe (CEPAL, 2012), la Convención Interamericana sobre la Protección de los Derechos Humanos de las Personas Mayores (OEA, 2015), el Consenso de Montevideo sobre Población y Desarrollo (CEPAL, 2013), la Agenda 2030 para el Desarrollo Sostenible (Naciones Unidas, 2015) y la Declaración de Asunción "Construyendo sociedades inclusivas: envejecimiento con dignidad y derechos" (CEPAL, 2017).

En este marco, el presente documento plantea un diagnóstico de la situación de las personas mayores frente a los posibles impactos del COVID-19 sobre ellas, tomando en consideración factores como el envejecimiento poblacional, las condiciones de salud, los arreglos domiciliarios y la corresidencia, y el acceso a infraestructura básica (agua y saneamiento) y a los sistemas de protección social. Por último, se presentan algunas acciones nacionales puestas en marcha para disminuir el impacto de la pandemia y se plantean recomendaciones para enfrentar los devastadores efectos sociales y económicos del COVID-19 en las personas mayores, tanto en la crisis como en la fase de recuperación, a fin de evitar que queden rezagadas o excluidas. Para ello se toman como hoja de ruta los diversos acuerdos regionales e internacionales.

\section{A. Vulnerabilidades sociodemográficas de las personas mayores frente al COVID-19}

La evolución del COVID-19 ha mostrado que la pandemia impacta en las personas de manera diferenciada. En este sentido, las personas mayores presentan vulnerabilidades específicas y, debido a las heterogeneidades existentes entre los países y en cada uno, es importante poner de relieve estos aspectos y trazar un breve panorama de la situación más reciente. Entre las vulnerabilidades sociodemográficas que afectan especialmente a las personas mayores, y que se abordan en este documento, están: el grado de evolución del envejecimiento poblacional, dado que la edad avanzada es un factor de riesgo; las condiciones de salud en términos de las enfermedades crónicas y los determinantes de la salud asociados a mayor riesgo; los arreglos domiciliarios y de corresidencia, dadas las recomendaciones de aislamiento social; el acceso a infraestructura básica (agua y saneamiento), esencial para contener la propagación del virus, y el acceso a sistemas adecuados de protección social, que, a su vez, influye en los determinantes de la salud de la población. 
Por otra parte, la pandemia también afecta de forma diferente a los distintos territorios. De hecho, la crisis sanitaria y económica ha exacerbado la vulnerabilidad de América Latina y el Caribe, una región caracterizada por una profunda desigualdad en diferentes dimensiones, altos niveles de pobreza y debilidad de los sistemas de protección social y de salud, al tiempo que ha puesto las desigualdades socioeconómicas y de acceso a los servicios de salud y protección social aún más en evidencia, en particular en los grupos más vulnerables de la población, como las personas mayores.

En este contexto, diferentes instancias internacionales, así como organizaciones de la sociedad civil de la región, han realizado declaraciones y emitido documentos referentes a las personas mayores y el COVID-19 donde se sostiene que los Estados deben proteger el derecho a la vida de esta población, exigiendo su respeto, independientemente de la edad de las personas, así como su defensa y promoción (Cisternas y Pineda, 2020; Huenchuan, 2020a y 2020b). En el recuadro 1 se presenta una breve síntesis de estos comunicados y declaraciones respecto del derecho a la vida de las personas mayores y recomendaciones bioéticas durante la pandemia de COVID-19.

Recuadro 1

Principales llamados a los Estados a garantizar los derechos de las personas mayores durante la pandemia de COVID-19

A fines de marzo se emitió una declaración conjunta de la Enviada Especial del Secretario General sobre la Discapacidad y la Accesibilidad y la Experta Independiente sobre el disfrute de todos los derechos humanos por las personas mayores. En dicha declaración se realizan una serie de recomendaciones bioéticas a los Estados para que las apliquen en las acciones que emprendan durante esta pandemia. Entre estas recomendaciones se destacan las siguientes: i) toda persona con discapacidad y toda persona mayor infectada con COVID-19 tiene derecho a acceder a unidades de cuidados intensivos, incluidos los sistemas de ventilación mecánica y otros apoyos para salvar su vida, en igualdad de condiciones con las demás. La vida de toda persona tiene igual valor; ii) ser una persona con discapacidad o ser una persona mayor no será una condición o determinante para negar u omitir el acceso a cuidados intensivos, incluidos los sistemas de ventilación mecánica y todos los apoyos para la vida, cuando se requieran, con absoluta independencia de la cobertura de los seguros de salud, si los hubiere; iii) la denegación u omisión puede calificarse como discriminación por motivo de discapacidad de acuerdo con la Convención sobre los Derechos de las Personas con Discapacidad, artículo 11, o discriminación por edad en la vejez de acuerdo con la Convención Interamericana sobre la Protección de los Derechos Humanos de las Personas Mayores, artículo 12; iv) la persona con discapacidad y la persona mayor infectada con COVID-19 siempre tendrán derecho al trato digno, a su autonomía en la toma de decisiones, el respeto a su voluntad y sus preferencias, al consentimiento libre e informado, y a la privacidad de sus datos personales; v) la persona con discapacidad y la persona mayor infectada con COVID-19 tendrán derecho a recibir toda la información pública sobre el COVID-19 de manera oportuna y accesible, utilizando ajustes razonables, si fueren necesarios.

En abril de 2020, la Comisión Interamericana de Derechos Humanos (CIDH), en el marco de su Sala de Coordinación y Respuesta Oportuna e Integrada a la crisis en relación con la pandemia del COVID-19 (SACROI COVID-19) instó a los Estados a brindar una protección reforzada a las personas mayores de la región, quienes se encuentran en una situación de mayor vulnerabilidad, y a adoptar las medidas necesarias para garantizar sus derechos, de acuerdo con la Convención Interamericana sobre la Protección de los Derechos Humanos de las Personas Mayores y con los estándares y las recomendaciones de su resolución núm. 1/2020 "Pandemia y Derechos Humanos en las Américas".

La CIDH manifiesta su preocupación por los altos índices de infección, ingreso en hospitales y mortalidad de personas mayores registrados en el último mes. La Comisión urge a los Estados a garantizarles el derecho a la salud física y mental, adoptando las medidas necesarias a fin de prevenir los contagios en todos los ámbitos y particularmente en residencias de largo plazo, hospitales y centros de privación de libertad. Para ello debe dárseles prioridad en el acceso a las pruebas de COVID-19. También resalta que, ante el agravamiento de la crisis y la subsecuente escasez de material médico, las personas mayores están expuestas a un mayor grado de discriminación y estigmatización en los servicios de salud, por ejemplo, al momento de hacer un triaje o asignar respiradores, a fin de garantizar su derecho a la vida, salud e integridad personal, y evitar toda forma de discriminación por motivos de edad o edadismo.

Fuente: Comisión Económica para América Latina y el Caribe (CEPAL), sobre la base de Comisión Interamericana de Derechos Humanos (CIDH), "La CIDH urge a los Estados a garantizar los derechos de las personas mayores frente a la pandemia del COVID-19", Comunicado de Prensa, Washington, D.C., 23 de abril de 2020 [en línea] https://www.oas.org/es/cidh/prensa/comunicados/2020/088.asp; Naciones Unidas, "Declaración conjunta: el derecho a la vida de las personas con discapacidad y personas mayores infectadas por el COVID-19", Nueva York, 2020 [en línea] https://www.un.org/development/desa/disabilities/wp-content/uploads/sites/15/2020/04/Versi\%C3\%B3n2Decl-Est\%C3\%A1ndar-Bioet-Dpcd-ES20abril.pdf. 
En esta misma línea, el Consenso de Montevideo sobre Población y Desarrollo, en el capítulo C "Envejecimiento, protección social y desafíos socioeconómicos", destaca en la medida prioritaria 22 la importancia de "erradicar las múltiples formas de discriminación que afectan a las personas mayores, incluyendo todas las formas de violencia contra mujeres y hombres mayores, teniendo en cuenta las obligaciones de los Estados con respecto a un envejecimiento con dignidad y derechos". Esta medida prioritaria está muy acorde con la situación que viven las personas mayores durante la pandemia en nuestra región. Asimismo, la medida prioritaria 24 llama a "otorgar la más alta prioridad a las personas mayores en los planes de prevención, mitigación y atención de desastres, incluidas la preparación para los desastres, la capacitación de trabajadores en la prevención y atención de situaciones de emergencia, y la disponibilidad de bienes y servicios". Esta medida prioritaria establecida en el Consenso toma gran fuerza y validez durante esta emergencia sanitaria en la región, reforzando lo que se indica en la Convención Interamericana sobre la Protección de los Derechos Humanos de las Personas Mayores. Asimismo, la Agenda 2030 y el Objetivo 3 estipulan que se debe garantizar una vida sana y promover el bienestar para todos a todas las edades. La pandemia es un punto de inflexión que demanda a los Estados una preparación para las emergencias sanitarias, pero además obliga a que destinen recursos para un buen manejo de esta situación, especialmente en lo que atañe a las personas mayores.

\section{Envejecimiento poblacional y efectos diferenciales del COVID-19 por edad y sexo}

América Latina y el Caribe tiene alrededor de 654 millones de habitantes, poco más de la mitad de los cuales son mujeres. El 24\% de esta población tiene menos de 15 años y las personas mayores (60 años y más) representan el 13\%. Para 2050 se proyecta que las personas mayores representarán casi el 25\% de la población de la región, mientras que los menores de 15 años disminuirán al 17\%. Se estima que el número de personas de 60 años y más superará por primera vez el de niños menores de 15 años alrededor de 2038 (Naciones Unidas, 2019a).

Otra tendencia importante a ser considerada es el envejecimiento entre las personas mayores. Entre los que alcanzan edades más avanzadas se registra un aumento considerable (véase el gráfico 1). El grupo de personas muy mayores (80 años y más), que actualmente representa el 1,9\% del total de la población (unos 12,4 millones de personas), se incrementará a una tasa especialmente rápida y se proyecta que superará los 41 millones de personas en los próximos 30 años (Naciones Unidas, 2019a). Esta tendencia es significativa porque dicho grupo, en general, tiene necesidades y capacidades muy diferentes respecto de los demás grupos de edades. Además, las mujeres, que tienen una esperanza de vida y una sobrevida mayor que los hombres, están sobrerrepresentadas entre las personas mayores, especialmente en el grupo de 80 años y más, lo que tiene importantes consecuencias para las políticas y acciones de salud y de cuidados. Actualmente, entre los mayores de 60 años hay 81 hombres por cada 100 mujeres en la región, en tanto que entre los de 80 años y más hay solo 64 hombres por cada 100 mujeres.

La heterogeneidad de los procesos demográficos, expresada en términos del porcentaje de personas mayores en la población y los diferenciales por sexo en la región, puede verse en el gráfico 2. Hay países como Cuba, Uruguay, Chile y la Argentina en los que los niveles de envejecimiento ya están en una fase bien avanzada en 2020, con una quinta parte de la población que tiene 60 años y más y con diferenciales por sexo significativos. En el otro extremo, con un proceso de envejecimiento por debajo del promedio de la región, y en una fase muy inicial, se ubican algunos países de Centroamérica y el Caribe, como Guatemala, Honduras, Haití y Nicaragua. En todos se registran diferenciales importantes por sexo, con más mujeres entre las personas en edades avanzadas.

La Organización Mundial de la Salud (OMS) define la pandemia por tres características que la hacen única y devastadora: i) la velocidad y la escala de expansión; ii) la gravedad de la enfermedad, con alta letalidad y mortalidad, principalmente en personas mayores; y iii) su poder de disrupción social y económica debido a las medidas necesarias para contener el virus (OMS, 2020a). Por ello, ha propuesto que los países deben "detectar los casos, 
someterlos a pruebas, aislarlos y atenderlos, y poner en cuarentena a los contactos para controlar la transmisión" (OMS, 2020a, pág. 8). Entre otras cosas, las acciones puestas en marcha, el momento de la toma de decisiones y la cooperación de la población hicieron que la evolución de la pandemia, que aún se encuentra en curso, fuera distinta en cada país.

\section{Gráfico 1}

América Latina y el Caribe: evolución de la población de personas mayores por sexo, 1960-2100

(En porcentajes)

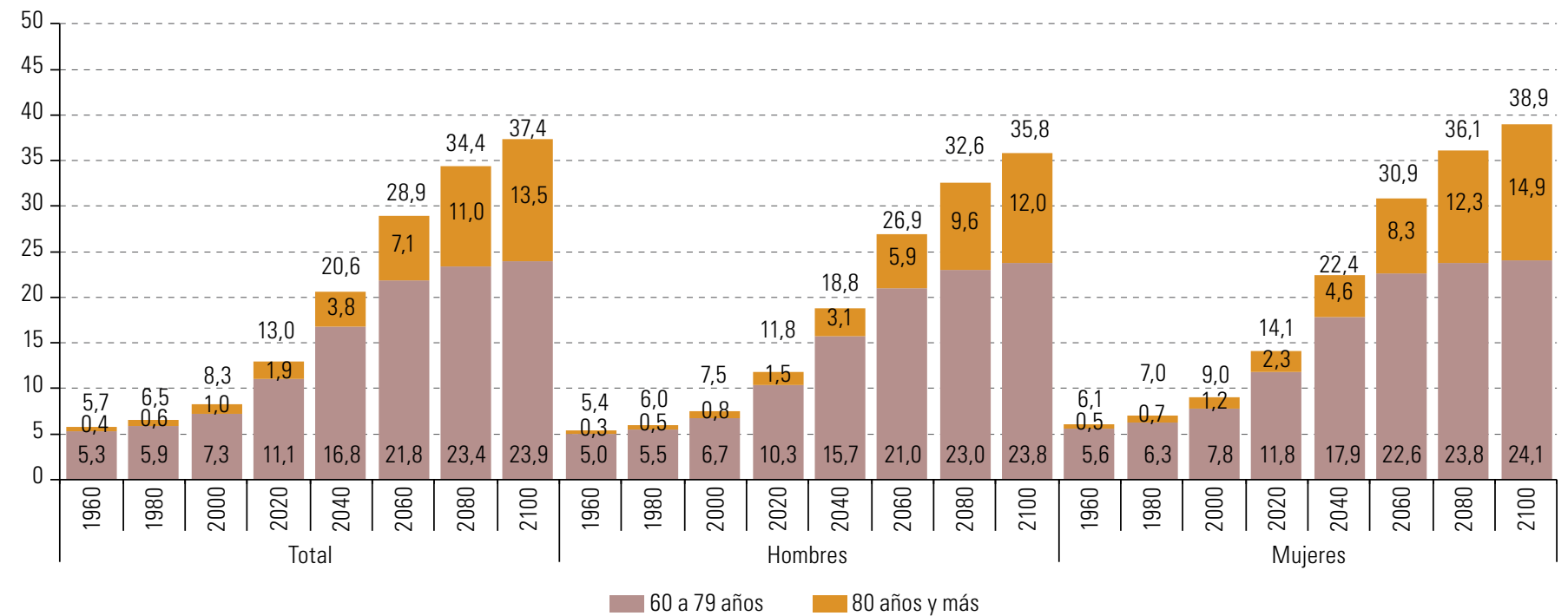

Fuente: Naciones Unidas, World Population Prospects: The 2019 Revision, Nueva York, 2019.

Gráfico 2

América Latina y el Caribe: población de 60 a 79 años y de 80 años y más, por sexo, 2020

(En porcentajes)

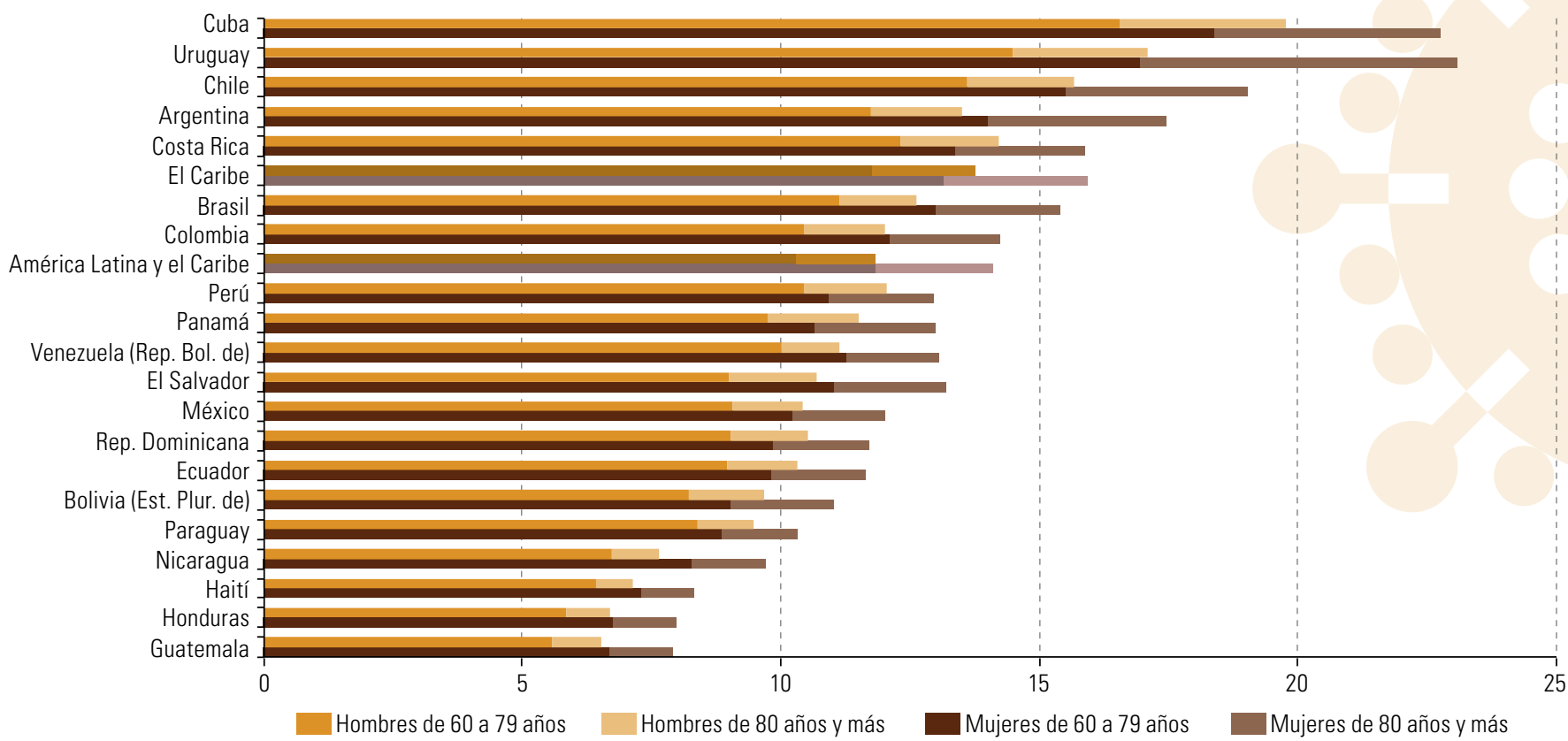

Fuente: Naciones Unidas, World Population Prospects: The 2019 Revision, Nueva York, 2019. 
La información sobre el número de personas infectadas y las defunciones por edad y sexo es esencial, pues desde un primer momento, con la evolución de la pandemia en China, Italia y España, se supo que las personas mayores eran las más afectadas por el agravamiento y la fatalidad del COVID-19. Cuando la pandemia alcanzó los 100 días desde el reconocimiento del primer caso de la enfermedad por parte de la OMS, se constató que el contagio solía ocurrir de distinta manera en los distintos países, pero que la tasa de letalidad podía estar por encima del 3\% en promedio, y que se incrementaba con la edad hasta alcanzar el 15\% en pacientes con 80 años y más (OMS, 2020a)

Fue así como, tras el inicio del brote, utilizando datos de China e Italia, los dos primeros países más afectados por la pandemia, algunos autores buscaron entender los efectos de la infección en las poblaciones con diferentes composiciones por edad y sexo (Dowd y otros, 2020; Promislow, 2020). Los datos mostraron que el riesgo de agravamiento y muerte en estos dos países era más alto entre las personas mayores y aún más entre los hombres que entre las mujeres. Dowd y otros (2020) subrayan que el análisis apunta a la importancia de tomar estos resultados en cuenta en la estrategia contra el COVID-19, debido a los mecanismos biológicos del envejecimiento que, en general, se suman a la presencia de comorbilidades, otro factor de riesgo muy asociado a los casos de agravamiento de la enfermedad. Guilmoto (2020) amplía el análisis sobre los posibles efectos de la edad y el sexo en la evolución del COVID-19, utilizando datos de países de Europa Occidental y los Estados Unidos. El autor llama la atención sobre el hecho de que los datos de defunciones presentan subregistros importantes y diferenciales por distintos factores (como la edad), vinculados principalmente a las muertes registradas en los hogares, tal como ocurrió en Italia. Una importante conclusión es que el gradiente de edad de la mortalidad por COVID-19 es más pronunciado que el de la mortalidad general, lo que causa una mayor concentración de muertes en la vejez (Guilmoto, 2020, pág. 11)

En este momento, entretanto, la información sistematizada y desglosada por edad y sexo respecto de los casos confirmados y de fallecidos por COVID-19 en los países de América Latina y el Caribe es insuficiente e incompleta como para confirmar si los hallazgos de otras regiones se aplican en esta ${ }^{2}$. A pesar de las incertidumbres y de las deficiencias de los datos, es fundamental trazar panoramas de cómo cada grupo poblacional está reaccionando biológicamente a la enfermedad en el corto plazo y cuáles serán las probables consecuencias a mediano y largo plazo para que las acciones contra la pandemia sean efectivas y se respeten los derechos de todas las personas, sobre todo el derecho a la vida sana y digna.

Con los datos de algunos países, aunque sin que todos ellos estén utilizando los mismos tramos de edad, la misma distribución por sexo o la misma precisión en el diagnóstico y clasificación de defunciones por COVID-19, la información disponible confirma el perfil de mayor porcentaje de muertes entre las personas mayores (véase el cuadro 1). Se observan tendencias diferenciadas respecto de las registradas en algunos países de Europa y los Estados Unidos, que permiten algunas comparaciones. En América Latina, la mortalidad ha sido menos concentrada entre las personas mayores, en especial las muy mayores (80 años y más), en parte por tener una estructura etaria relativamente más joven que la europea. Los países más desarrollados presentan un porcentaje superior al $95 \%$ de personas de 60 años y más entre las muertes e incluso más de la mitad de los fallecidos tenían 80 años y más.

Respecto de la comparación por sexo, si bien no todos los países divulgan estos datos completos, y la pandemia aún sigue su curso, las informaciones preliminares disponibles muestran que las personas mayores, tanto hombres como mujeres, son quienes estarían registrando mayores niveles de mortalidad por COVID-19 con respecto a la población más joven.

Se analizaron los datos disponibles en algunos países, como el Brasil, México y el Perú, donde se constatan que fueron muchos más hombres que mujeres de todas las edades los que perdieron la vida a causa del COVID-19, a razón de dos o tres veces más, dependiendo

Cabe destacar que hay muy buenos ejemplos de divulgación de datos en sistemas de vigilancia epidemiológicay conocimiento y tecnología disponibles en la región. Entre otras cosas, hace falta sistematización y organización, así como estandarización de los conceptos utilizados, de los casos confirmados y sospechosos. 
de la edad (véase el gráfico 3). El Perú es el país que registra las razones más altas. Una de las explicaciones para este resultado podría ser la mayor infección registrada por los hombres, que pueden estar más expuestos, y también los factores de riesgo de salud asociados a comorbilidades diferenciales por sexo, que pueden favorecer a las mujeres, con una menor gravedad de la enfermedad respecto de los hombres. La excepción a ese resultado se presenta en las mujeres menores de 19 años y las mujeres muy mayores (90 años y más) en el Brasil, que presentan más casos de muertes en comparación con los hombres.

Cuadro 1

Distribución de muertes por COVID-19 por grupos etarios, por países

(En porcentajes y números)

\begin{tabular}{|c|c|c|c|c|c|}
\hline & 60 años y más & 70 años y más & 80 años y más & Muertes & Fecha \\
\hline Brasila & 74,9 & 52,3 & 26,8 & 121381 & 31/08/2020 \\
\hline México & 59,1 & 31,5 & 10,6 & 64414 & 31/08/2020 \\
\hline Perú & 69,5 & 41,4 & 16,9 & 28994 & $31 / 08 / 2020$ \\
\hline Chile & 84,0 & 62,6 & 34,5 & 11321 & 01/09/2020 \\
\hline Colombia & 73,6 & 50,6 & 25,5 & 19663 & $31 / 08 / 2020$ \\
\hline Españab & 94,2 & 83,2 & 54,6 & 29152 & 01/09/2020 \\
\hline Italiac & 95,4 & 85,3 & 59,0 & 35944 & $31 / 08 / 2020$ \\
\hline \multirow[t]{2}{*}{ Suecia } & 96,0 & 89,1 & 67,5 & 5813 & 01/09/2020 \\
\hline & 65 años y más & 75 años y más & 85 años y más & Muertes & Fecha \\
\hline Ecuador $^{d}$ & 59,1 & n.d. & n.d. & 9911 & $22 / 08 / 2020$ \\
\hline Reino Unido & 89,4 & 74,6 & 42,3 & 52026 & $14 / 08 / 2020$ \\
\hline Estados Unidos & 79,2 & 57,9 & 31,5 & 164276 & 26/08/2020 \\
\hline
\end{tabular}

Fuente: Comisión Económica para América Latina y el Caribe (CEPAL), sobre la base de información oficial de los respectivos países.

a Hasta el 24 de agosto de 2020 se registraron 143.149 muertes a causa del síndrome respiratorio agudo grave.

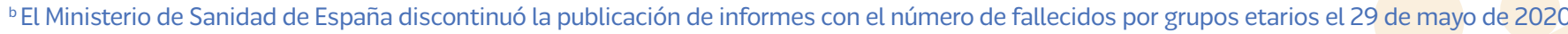
(informe núm. 120), por lo que los porcentajes corresponden a este informe y solo la cifra total refleja la situación del 1 de septiembre de 2020. ' El último informe con fallecimientos desagregados se publicó el 22 de julio de 2020 . El total de muertes corresponde a la fecha indicada.

${ }^{\mathrm{d}}$ Las defunciones corresponden al total de fallecidos confirmados y sospechosos, según el último boletín epidemiológico del gobierno.

\section{Gráfico 3}

Brasil (24 de agosto), México y Perú (31 de agosto): número de hombres por cada 100 mujeres fallecidas por COVID-19, por grupos etarios, 2020

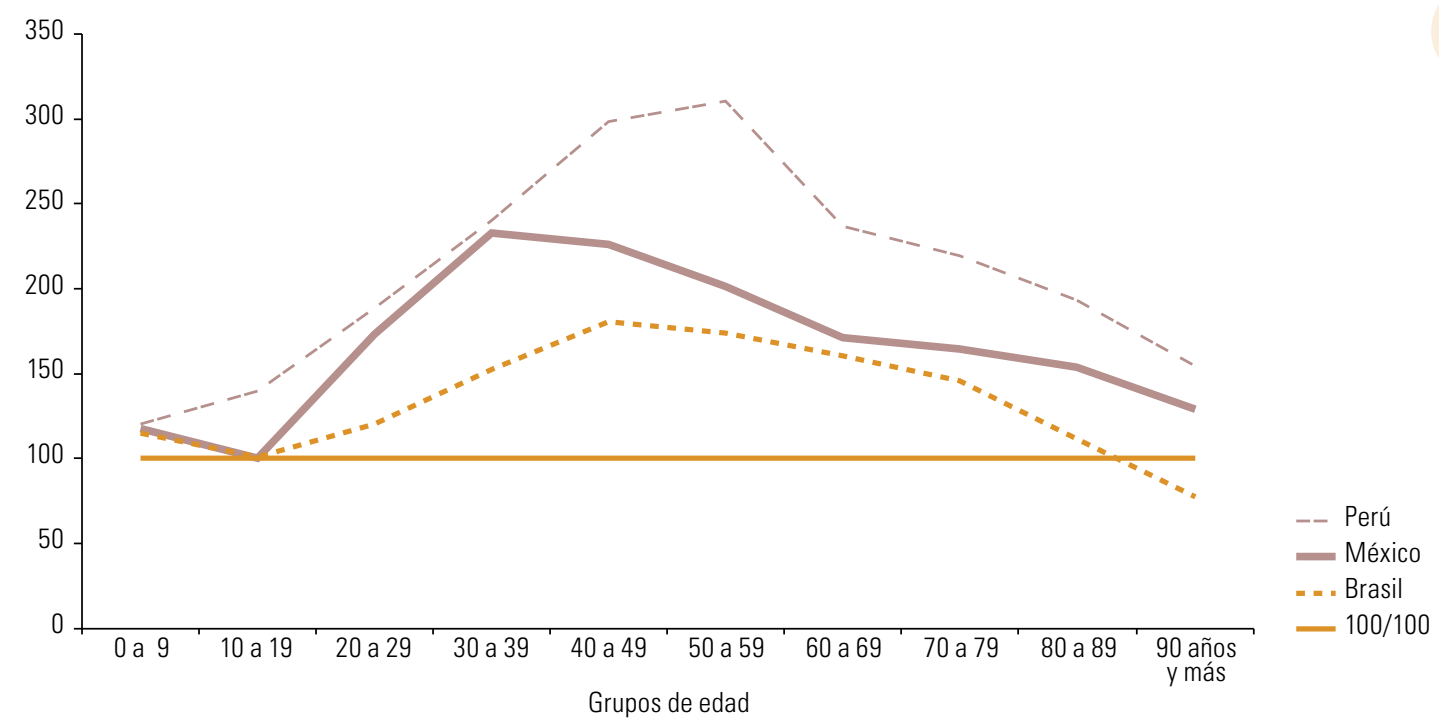

Fuente: Comisión Económica para América Latina y el Caribe (CEPAL), sobre la base de información oficial de los respectivos países. 


\section{Afecciones de salud de las personas mayores y efectos diferenciales del COVID-19 por morbilidad y otros factores}

Además de la edad, otro factor de riesgo, conocido a partir de la experiencia de los países en las etapas más avanzadas de la pandemia, y de acuerdo con lo que ya se ha señalado, es la existencia previa de enfermedades crónicas y múltiples morbilidades ${ }^{3}$.

La pandemia encontró a muchos países con sus sistemas de salud con grandes debilidades. Un informe reciente de la Comisión Económica para América Latina y el Caribe (CEPAL) y la Organización Panamericana de la Salud (OPS) indica que "se trata de sistemas de salud subfinanciados, segmentados y fragmentados, que presentan importantes barreras para el acceso' (CEPAL/OPS, 2020, pág. 4). Todos tuvieron que resolver de manera apresurada la posible falta de insumos y de personal de salud procurando evitar colapsos en los sistemas sanitarios. En este contexto, los planes de asistencia a la salud para enfrentar los momentos más duros de la pandemia debieron trazarse en paralelo con el intento de contener la expansión del virus por los territorios nacionales.

En la gran mayoría de los países de la región, las personas mayores y muy mayores se ven aquejadas en mayor grado por accidentes cerebrovasculares y cardiopatías isquémicas. Para considerar los riesgos de la población, más que saber la distribución relativa de las enfermedades, es importante conocer el porcentaje de la población que tiene estas enfermedades, ya que tendrá más probabilidades de necesitar hospitalización y ventilación mecánica.

A modo de ejemplo, el cuadro 2 presenta el porcentaje de personas de 60 años y más, por sexo, para tres grupos de enfermedades que han sido identificadas como las de mayor riesgo ante el COVID-19: enfermedades cardiovasculares (accidentes cerebrovasculares y cardiopatías isquémicas), enfermedades respiratorias crónicas y diabetes.

De acuerdo con los datos presentados, de un cuarto a un tercio de las personas de 60 años y más han sido diagnosticados con accidentes cerebrovasculares o cardiopatías isquémicas. Los hombres presentan porcentajes más altos respecto de las mujeres, lo que los ubica en una condición de mayor riesgo de agravamiento en caso de contraer COVID-19. En el caso de las enfermedades respiratorias crónicas, las diferencias por sexo son significativas en la gran mayoría de los países y los hombres son los más afectados por la enfermedad.

La presencia de diabetes entre las personas mayores es la que registra mayor variación entre los países, con cifras que van desde un mínimo del 11\% hasta un máximo del 45\%. Además, en algunos países las mujeres mayores son las más afectadas por la enfermedad, aunque cabe notar que en los diferenciales de género en el control de las enfermedades ellas suelen ser las que se cuidan más de las enfermedades. De todas formas, sería necesario contar con datos más recientes y sobre control de las enfermedades para efectuar una comparación más precisa.

Otros factores de riesgo que hacen que las personas sean más vulnerables a enfermarse gravemente con COVID-19 son la obesidad, el hábito de fumar y otras afecciones que aumentan la necesidad de oxígeno o reducen la capacidad del cuerpo para usarlo adecuadamente (OMS, 2020a). Algunos países presentan datos sobre estas afecciones y en el gráfico 4 se muestra tanto la amplia variación entre los países de la región como el gran diferencial por sexo y edad en la prevalencia de obesidad y uso de tabaco.

Con relación a la obesidad, alrededor de un cuarto de las personas de 60 años y más fueron clasificadas como obesas en algunos países, aunque las de 80 años y más se incluyen en menor proporción. Sin embargo, cabe señalar que prácticamente en todos los países el porcentaje de mujeres en el grupo de personas obesas es más alto que el de los hombres. En cuanto al hábito de fumar, la situación por sexo se invierte, aunque la prevalencia de fumadores es más elevada para los hombres mayores y muy mayores.

Según la OMS (2020g), las personas con enfermedad cardiovascular (hipertensión o que han tenido o corren riesgo de tener un ataque cardíaco o un derrame cerebral), enfermedad pulmonar obstructiva crónica (EPOC), diabetes y cáncer parecen ser más vulnerables a enfermarse gravemente con el virus. 
Los datos de morbilidades preexistentes entre infectados de COVID-19 en los países de la región aún son muy escasos. Desde las primeras noticias sobre la enfermedad, la gravedad y la mortalidad se asociaron a la preexistencia de enfermedades crónicas. Entre las más comunes, de las que incluso aparecía más de una en los casos más graves, se encuentran las enfermedades cardiovasculares, la diabetes, las enfermedades respiratorias crónicas y la hipertensión, aunque personas con buena salud también presentaron cuadros graves.

Cuadro 2

América Latina y el Caribe: personas mayores (60 años y más), según enfermedades crónicas seleccionadas y sexo, alrededor de 2017 (En porcentajes)

\begin{tabular}{|c|c|c|c|c|c|c|c|c|c|}
\hline & \multicolumn{3}{|c|}{$\begin{array}{l}\text { Enfermedades cardiovasculares } \\
\text { (accidentes cerebrovasculares } \\
\text { y cardiopatías isquémicas) }\end{array}$} & \multicolumn{3}{|c|}{$\begin{array}{l}\text { Enfermedades } \\
\text { respiratorias crónicas }\end{array}$} & \multicolumn{3}{|c|}{ Diabetes } \\
\hline & Total & Hombres & Mujeres & Total & Hombres & Mujeres & Total & Hombres & Mujeres \\
\hline & \multicolumn{9}{|c|}{60 años y más } \\
\hline Argentina & 32,8 & 35,5 & 30,7 & 20,7 & 27,9 & 15,6 & 16,3 & 17,9 & 15,1 \\
\hline Bahamas & 29,5 & 30,8 & 28,6 & 17,6 & 21,4 & 14,6 & 22,5 & 23,6 & 21,6 \\
\hline Barbados & 33,4 & 34,6 & 32,4 & 16,7 & 20,2 & 14,0 & 27,9 & 26,7 & 28,8 \\
\hline Belice & 29,1 & 30,4 & 27,9 & 19,4 & 23,4 & 15,4 & 28,1 & 26,3 & 29,8 \\
\hline Bolivia (Estado Plurinacional de) & 26,8 & 27,5 & 26,2 & 20,0 & 23,7 & 16,7 & 15,5 & 16,3 & 14,8 \\
\hline Brasil & 30,1 & 34,3 & 26,7 & 22,2 & 27,9 & 17,8 & 12,0 & 12,3 & 11,7 \\
\hline Chile & 31,5 & 33,8 & 29,7 & 18,7 & 22,9 & 15,3 & 13,7 & 14,7 & 12,9 \\
\hline Colombia & 25,8 & 26,2 & 25,4 & 23,8 & 28,3 & 20,0 & 13,4 & 14,8 & 12,3 \\
\hline Costa Rica & 26,5 & 27,0 & 26,1 & 22,2 & 25,8 & 18,9 & 13,6 & 15,2 & 12,2 \\
\hline Ecuador & 27,1 & 27,6 & 26,6 & 15,0 & 18,7 & 11,8 & 15,0 & 15,4 & 14,6 \\
\hline El Salvador & 26,1 & 26,7 & 25,7 & 19,6 & 22,7 & 17,2 & 18,2 & 19,4 & 17,3 \\
\hline Guatemala & 27,1 & 28,0 & 26,3 & 18,9 & 22,9 & 15,5 & 23,0 & 25,3 & 21,2 \\
\hline Guyana & 30,2 & 32,0 & 28,6 & 17,8 & 21,1 & 14,8 & 31,2 & 30,0 & 32,2 \\
\hline Haití & 28,8 & 30,5 & 27,4 & 18,4 & 21,1 & 16,2 & 20,7 & 17,4 & 23,5 \\
\hline Honduras & 24,7 & 26,9 & 22,9 & 23,0 & 25,5 & 20,9 & 17,3 & 18,0 & 16,7 \\
\hline Jamaica & 31,0 & 32,3 & 29,8 & 18,9 & 23,5 & 14,7 & 34,7 & 31,1 & 38,0 \\
\hline México & 27,2 & 27,2 & 27,2 & 21,4 & 26,4 & 17,1 & 30,2 & 33,8 & 27,1 \\
\hline Paraguay & 31,3 & 35,0 & 27,8 & 19,4 & 23,9 & 15,1 & 21,6 & 20,3 & 22,8 \\
\hline Perú & 25,2 & 25,6 & 24,8 & 16,8 & 20,0 & 14,0 & 11,0 & 12,2 & 9,9 \\
\hline República Dominicana & 30,8 & 32,5 & 29,2 & 17,5 & 20,5 & 14,8 & 14,0 & 15,0 & 13,1 \\
\hline Suriname & 31,9 & 34,1 & 30,2 & 20,4 & 24,8 & 17,1 & 26,0 & 28,9 & 23,8 \\
\hline Trinidad y Tabago & 32,0 & 33,5 & 30,8 & 20,2 & 25,5 & 15,8 & 45,0 & 54,4 & 37,3 \\
\hline Uruguay & 34,1 & 36,1 & 32,7 & 23,8 & 33,5 & 17,2 & 12,3 & 13,4 & 11,5 \\
\hline
\end{tabular}

Fuente: Banco Interamericano de Desarrollo (BID), "Indicadores: panorama de envejecimiento y atención a la dependencia”, 2020 [en línea] https://www.iadb.org/es/panorama/indicadores; Instituto de Sanimetría y Evaluación Sanitaria, GBD Results Tool, Seattle, 2017 [base de datos en línea] http://ghdx.healthdata.org/gbd-results-tool. 
Gráfico 4

América Latina ( 5 países): personas de 60 años y más y de 80 años y más, por sexo

y factores de riesgo específicos (obesidad y hábito de fumar)

(En porcentajes)

\section{A. Obesidad}

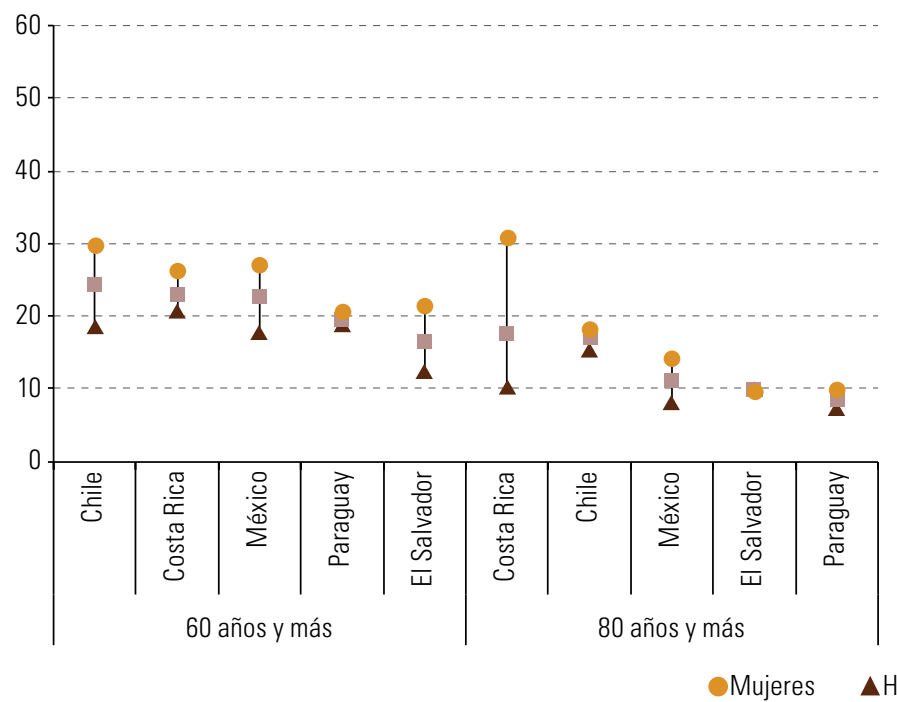

\section{B. Uso de tabaco}

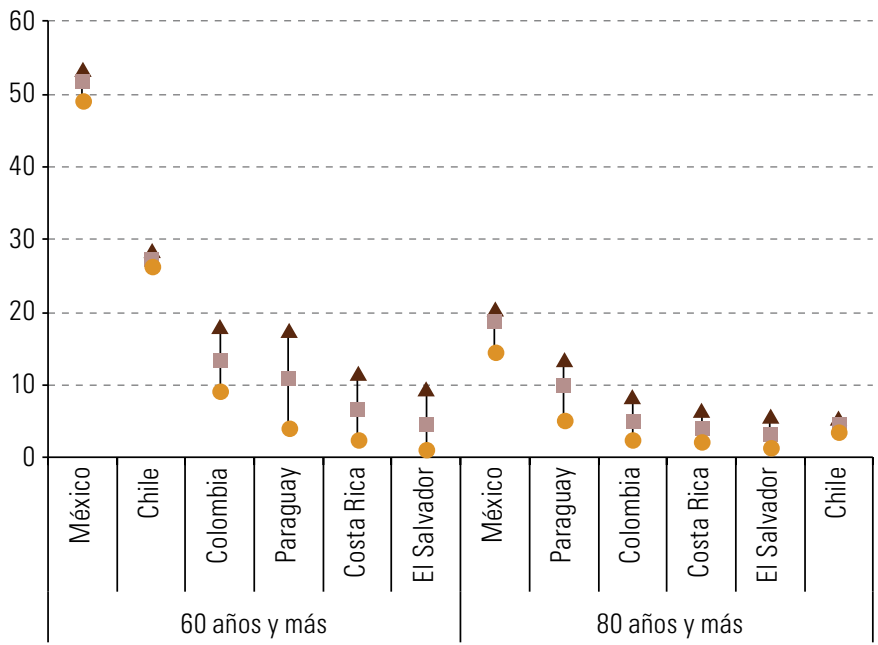

Fuente: Banco Interamericano de Desarrollo (BID), "Indicadores: panorama de envejecimiento y atención a la dependencia", 2020 [en línea] https://www.iadb.org/es/panorama/indicadores, y encuestas de los respectivos países.

Las desigualdades en las condiciones de salud y las fragilidades de salud de esta población, con perfil epidemiológico distinto al de los países desarrollados, sumadas a los problemas de acceso y calidad de los servicios en los sistemas de salud en los países en desarrollo, podrían incrementar aún más la letalidad y gravedad de la infección por COVID-19 entre las personas mayores en la región.

\section{Personas mayores con discapacidad}

Así como las comorbilidades que se señalaron en el caso de las personas mayores aumentan la gravedad de la enfermedad causada por el virus e incrementan la probabilidad de muerte, los diferentes tipos de discapacidad que las afectan también podrían incidir en una mayor probabilidad de contagiarse. Además, si la persona mayor ya está contagiada, dependiendo del tipo de discapacidad que presenta, puede experimentar una mayor gravedad de sus síntomas. La OMS indica que entre los factores que incidirían en un mayor riesgo de contraer COVID-19 entre las personas mayores con discapacidad están los obstáculos para emplear algunas medidas básicas de higiene. Por ejemplo, el lavado de manos no es una acción fácil de realizar si la persona mayor con discapacidad tiene dificultades físicas para frotarse las manos o si el lavamanos es de difícil acceso para una persona con movilidad reducida. Por otra parte, las personas ciegas o con visión reducida, que tienen la necesidad de tocar ciertos objetos a fin de obtener información del entorno para apoyarse físicamente, estarían más expuestas a contagiarse. A esto se suman los diferentes obstáculos para acceder a la información de salud pública (OMS, 2020f).

Por otra parte, las comorbilidades que presentan las personas mayores con discapacidad pueden aumentar el riesgo de presentar casos más graves de COVID-19 si contraen la infección. La OMS indica que esto se debe principalmente a que el COVID-19 "exacerba los problemas de salud existentes, en particular los relacionados con la función respiratoria o la función del sistema inmunitario, o con cardiopatías o diabetes". Además, las personas mayores con discapacidad "podrían encontrar mayores obstáculos para el acceso a la atención de salud" (OMS, 2020f, pág. 2). 
A nivel general, los porcentajes de personas con discapacidad en la región oscilan, según datos censales, entre un 4\% y un 24\% (González y Stang, 2014). La prevalencia se incrementó en la última década por efecto de la mejor captación de datos de las diferentes fuentes estadísticas, particularmente los censos y las encuestas ${ }^{4}$. Conforme aumenta la edad, la proporción de personas con discapacidad va aumentando, por lo que entre las personas mayores hay una proporción más elevada de personas con discapacidad

Un análisis que se remite a los resultados proporcionados por ocho países de la región que realizaron censos en el primer quinquenio de la década de 2010 muestra que alrededor de 41 de cada 100 personas mayores tenía algún tipo de discapacidad. Destacan el Brasil (más del 60\%), la República Dominicana y el Uruguay (45\%). La incidencia es más elevada en las mujeres que en los hombres: un $43 \%$ frente a un 38,8\% (Huenchuan, 2018).

Con datos de censos más recientes se advierte que la tendencia es muy similar: un aumento de la proporción de personas con discapacidad a mayor edad y un leve predominio femenino. Alrededor del 14\% de las personas de 60 años y más de Guatemala y Colombia tienen algún tipo de discapacidad, mientras que en las personas mayores del Perú este porcentaje aumenta al 35\%. A los 80 años y más, la prevalencia de discapacidad aumenta aún más: alrededor del $30 \%$ de las personas mayores de Guatemala y Colombia y el 58\% de las personas mayores del Perú tienen alguna discapacidad (véase el cuadro 3). En todos los países incluidos en el cuadro 3 este porcentaje es levemente mayor en las mujeres que en los hombres.

Cuadro 3

Guatemala, Colombia y Perú: personas mayores con discapacidad, según grupos de edad y sexo, censos de la década de 2010

(En porcentajes)

\begin{tabular}{|c|c|c|c|c|c|c|c|c|c|}
\hline \multirow[b]{2}{*}{ País } & \multicolumn{3}{|c|}{ Hombres } & \multicolumn{3}{|c|}{ Mujeres } & \multicolumn{3}{|c|}{ Ambos sexos } \\
\hline & $\begin{array}{c}60 \text { a } 79 \\
\text { años }\end{array}$ & $\begin{array}{l}80 \text { años } \\
\text { y más }\end{array}$ & $\begin{array}{l}60 \text { años } \\
\text { y más }\end{array}$ & $\begin{array}{c}60 \text { a } 79 \\
\text { años }\end{array}$ & $\begin{array}{l}80 \text { años } \\
\text { y más }\end{array}$ & $\begin{array}{l}60 \text { años } \\
\text { y más }\end{array}$ & $\begin{array}{c}60 \text { a } 79 \\
\text { años }\end{array}$ & $\begin{array}{l}80 \text { años } \\
\text { y más }\end{array}$ & $\begin{array}{l}60 \text { años } \\
\text { y más }\end{array}$ \\
\hline Guatemala & 10,0 & 30,8 & 13,0 & 10,9 & 31,6 & 14,0 & 10,5 & 31,2 & 13,5 \\
\hline Colombia & 11,0 & 28,0 & 13,4 & 11,5 & 30,3 & 14,6 & 11,3 & 29,4 & 14,1 \\
\hline Perú & 28,0 & 57,0 & 32,5 & 33,7 & 58,3 & 38,0 & 31,0 & 57,7 & 35,4 \\
\hline
\end{tabular}

Fuente: Comisión Económica para América Latina y el Caribe (CEPAL), sobre la base de censos de población y vivienda de los respectivos países.

Las personas mayores con discapacidad enfrentan barreras específicas para realizar las actividades de la vida diaria debido al COVID-19. Las restricciones de quedarse en casa para no contraer la enfermedad en general no consideran sus necesidades, de modo que crean nuevos riesgos para su autonomía, salud y vida (ACNUDH, 2020). Las que dependen de apoyos (ya sean formales o informales de familiares o amigos) para realizar actividades de la vida diaria, durante la pandemia se encuentran sin ellos debido a las restricciones de movimiento en el territorio por las cuarentenas implementadas en los países y las medidas de distanciamiento físico que se han establecido. Esto tiene efectos negativos en las personas mayores con discapacidad pues hay un mayor riesgo de no tener acceso a alimentos, bienes esenciales y medicamentos. Ello puede obligarlos a salir por su cuenta (cuando pueden hacerlo) a adquirir estos insumos básicos, lo que aumenta la probabilidad de contagio. El hecho de no contar con los apoyos necesarios también influye en la realización de actividades cotidianas básicas como bañarse, cocinar o alimentarse, acciones necesarias para la subsistencia diaria (ACNUDH, 2020).

\footnotetext{
Siguiendo recomendaciones internacionales y nacionales, algunos países de América Latina mejoraron la captación de datos sobre las personas con discapacidad en los censos de población de la década de 2010 lo que se logró al pasar de un enfoque biomédico a uno biosocial o social en la manera de preguntar por las limitaciones. En estos censos se indagó principalmente acerca de las limitaciones en la visión, auditivas, de movilidad o para caminar, para recordar o concentrarse, para realizar tareas de cuidado personal y de comunicación. Si bien los datos obtenidos de esta forma aún presentan ciertas restricciones, es la información con que se cuenta para conocer el porcentaje de personas con discapacidad de los países y de algunos grupos específicos, en este caso, las personas mayores.
} 
Otra dificultad que se ha presentado durante esta emergencia sanitaria entre las personas mayores con discapacidad es el difícil acceso a la información pública sobre las medidas para enfrentar el COVID-19, pues esta no se comunica ni difunde sistemáticamente en formatos accesibles (lo que incluye, por ejemplo, interpretación en lenguaje de señas de la información relevante acerca de la enfermedad, subtítulos cuando se brindan indicaciones para el manejo de la pandemia y formatos fáciles de leer). Esto obstaculiza el acceso a información con la que estas personas deben contar para tomar las medidas de protección y resguardo frente al virus, lo que puede incidir en una mayor probabilidad de contagio.

En muchas ocasiones, los datos agregados a escalas de países ocultan marcadas diferencias a escalas geográficas menores. La información respecto de las personas con discapacidad así lo muestra en los tres países de los que se cuenta con información reciente a partir de los censos. Si el análisis se centra a escala de divisiones administrativas menores (municipios en Colombia y Guatemala, y distritos en el Perú), las diferencias son significativas.

En el mapa 1 se muestra el porcentaje de personas de 80 años y más con discapacidad. En Guatemala (véase el mapa 1.A), los municipios de Usumatlán, San José La Arada, Santa Apolonia, Patzité, Santa Cruz La Laguna, Santa Catarina Mita y San Raymundo presentan porcentajes superiores al 50\% de personas mayores de 80 años con discapacidad. En Colombia (véase el mapa 1.B) hay 322 municipios que presentan más del $50 \%$ de personas mayores de 80 años con discapacidad. Entre ellos se destacan: San Juanito (100\%), en el departamento de Meta; Puerto Alegría (100\%), en el departamento de Amazonas; Pana (83\%), en Guainía; El Tablón de Gómez (77,7\%), en el departamento de Nariño, y Mologavita (75\%), en el departamento de Santander. En el Perú (véase el mapa 1.C), 1.403 distritos de un total de 1.876 tienen más de un 50\% de personas de 80 años y más con discapacidad. Entre estos se destacan: Recta (100\%), en el departamento de Amazonas; Soplin (100\%), en el departamento de Loreto; Pararca (96,2\%), en el departamento de Ayacucho; Quilahuani (95,5\%), en el departamento de Tacna; y Masma Chicche (95\%), en el departamento de Junín.

En general, la población de 80 años y más con discapacidad se compone de personas con una alta dependencia de cuidados y muy baja autonomía. Muchas de ellas pueden estar postradas y demandar apoyo durante todo el día. Por tanto, deben contar con personas que les brinden cuidados diarios, ya sea en su casa o en establecimientos de larga estadía. De allí la relevancia de conocer a nivel local el número de personas que se encuentran en esta situación, así como su distribución territorial, a fin de focalizar las acciones y realizar una buena gestión en términos de apoyo a la persona mayor y su familia.

Los gobiernos locales están en contacto directo con la población, y las autoridades de estas divisiones administrativas menores reciben las demandas de apoyo en temas de salud y cuidados, como visitas médicas a domicilio para las personas mayores que están postradas o traslados al centro de salud primario para atención de urgencia, controles médicos o entrega de medicamentos. Las demandas de apoyo económico se asocian a gastos de bolsillo en medicamentos, apoyos para compras de alimentación especial o subsidios en el pago de servicios de primera necesidad. La emergencia sanitaria ha agudizado los problemas socioeconómicos de las familias. La crisis económica en la región ha incidido en un marcado aumento del desempleo y la pobreza monetaria en todos los países. Por tanto, los gobiernos locales deben canalizar estas demandas e intentar realizar una adecuada gestión de los recursos para satisfacerlas. Además, tienen que garantizar los derechos de accesibilidad universal de las ciudades y los asentamientos humanos, así como de acceso a la salud y apoyos económicos para personas en situación de pobreza, teniendo siempre en cuenta la realidad de cada contexto local y las necesidades ciudadanas (Cisternas y Pineda, 2020). 
Mapa 1

Guatemala, Colombia y Perú: personas de 80 años y más con discapacidad, por divisiones administrativas menores, censos de la década de 2010

(En porcentajes)

\section{A. Guatemala}

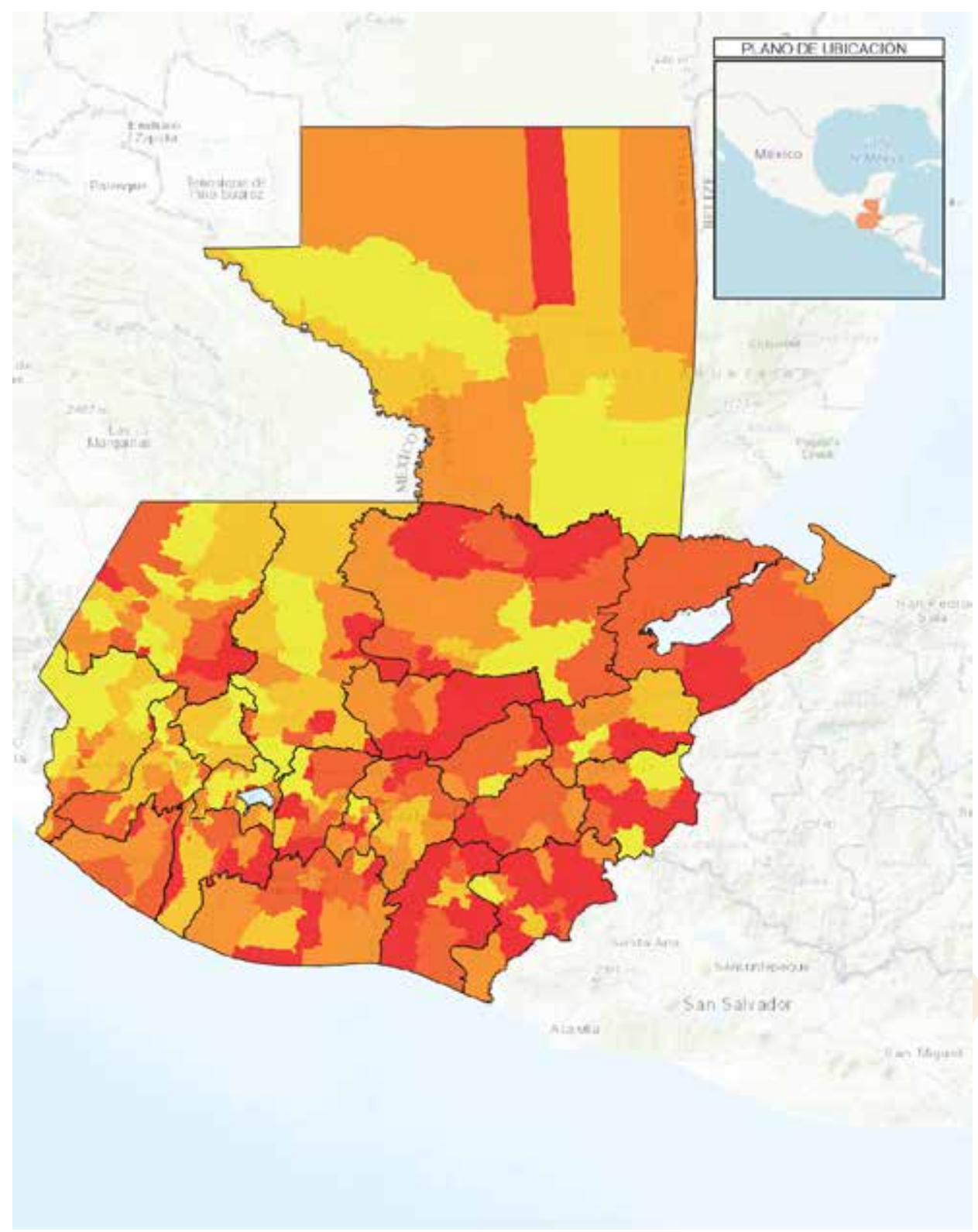

Menos de $24 \%-24 \%$ a $29,1 \%-29,1 \%$ a $33,7 \%-33,7 \%$ a $38,8 \%-38,8 \%$ a $66,5 \%$

Límites $\square$ Límite departamental 


\section{B. Colombia}

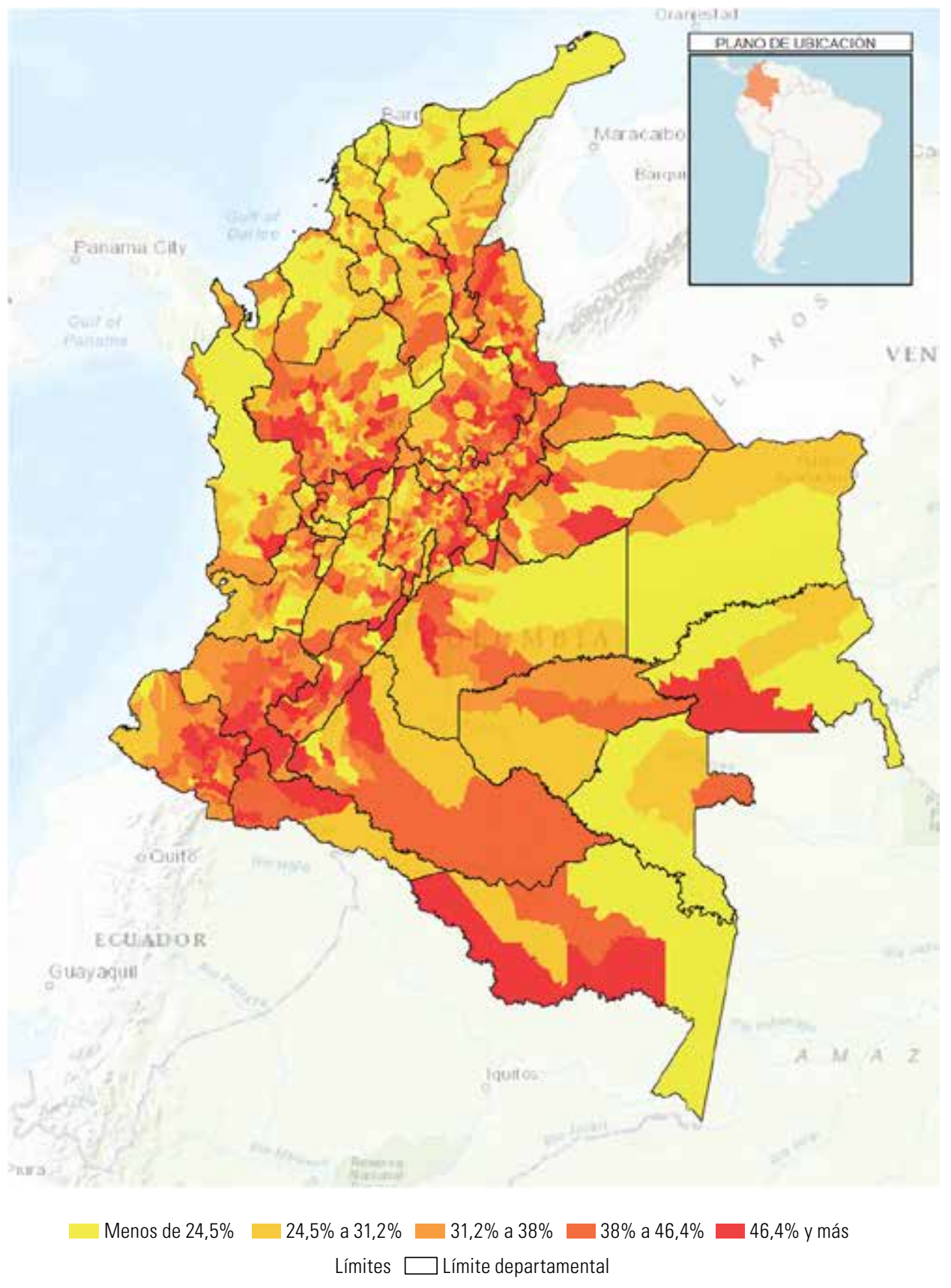




\section{Perú}

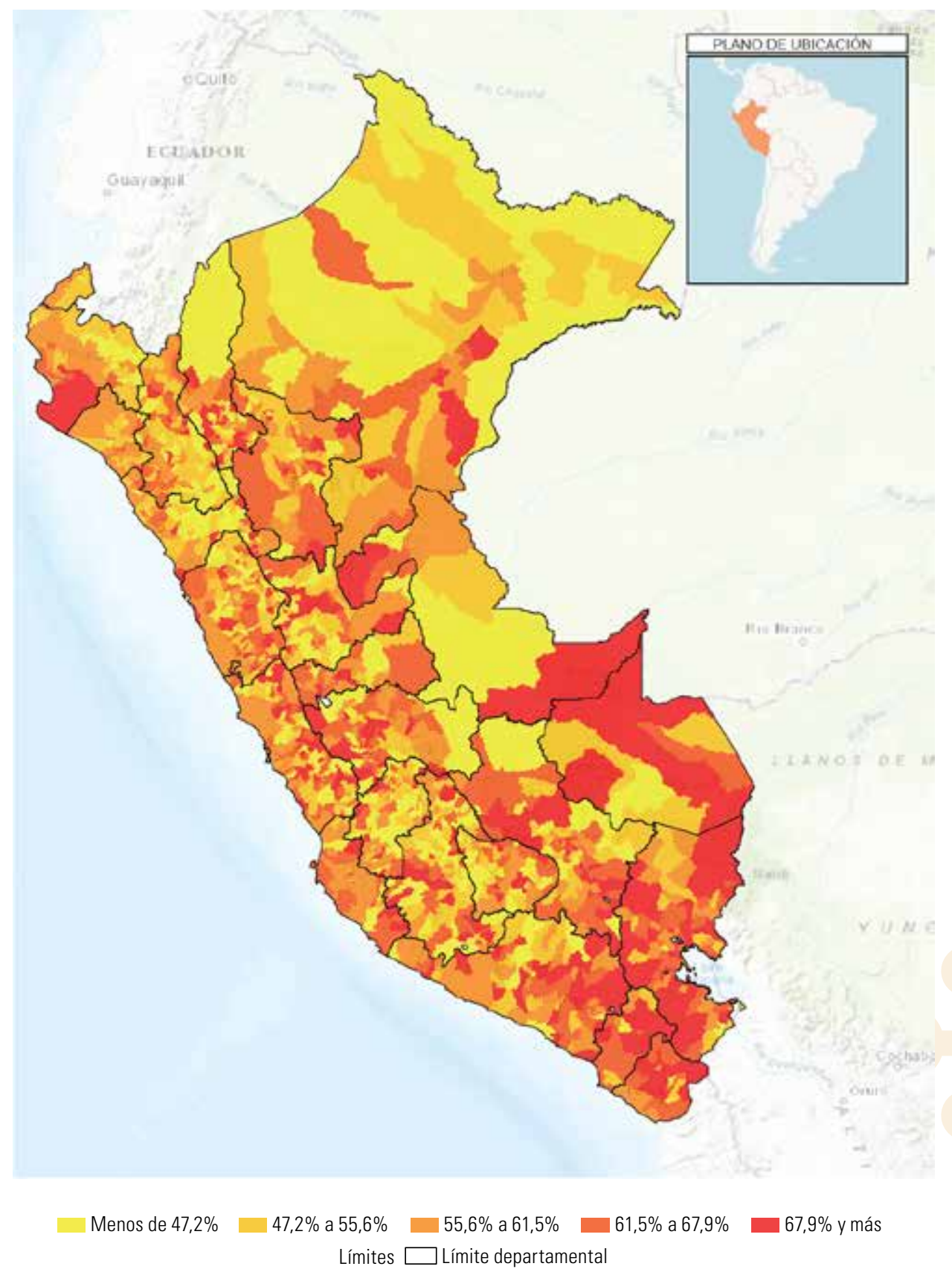

Fuente: Comisión Económica para América Latina y el Caribe (CEPAL), sobre la base de censos de población y vivienda de los respectivos países. Nota: Los datos de Guatemala y Colombia corresponden a los censos de 2018 y los del Perú a los de 2017.

\section{Arreglos domiciliarios y corresidencia de las personas mayores}

La pandemia ha exacerbado y profundizado las desigualdades que ya existían en la región, al tiempo que ha puesto de manifiesto las vulnerabilidades que afectan los derechos de algunos grupos de población específicos, como las personas de edad. Los mayores riesgos del COVID-19 son evidentes según el tipo de arreglos residenciales que los afectan. En 
el caso de las personas mayores que residen en hogares familiares multigeneracionales, la corresidencia intergeneracional puede ser uno de los principales vectores de contagio (Esteve, Permanyer y Boertien, 2020). Las que viven solas pueden enfrentar barreras para obtener información precisa, alimentos, medicamentos y otros suministros esenciales durante las condiciones de cuarentena, en tanto que las que viven en centros de atención a largo plazo, como hogares de ancianos y centros de rehabilitación, son particularmente vulnerables a las infecciones y los resultados adversos del COVID-19.

\section{a) Corresidencia intergeneracional como vector de contagio}

La información sobre arreglos residenciales de los diferentes grupos de edad, que muestran la frecuencia relativa en que las diferentes generaciones comparten un espacio cotidiano (como la vivienda o los hogares dentro de las viviendas), ofrece datos sugerentes de interacción regular a escala doméstica, que se captan de forma directa mediante censos y encuestas.

La diversificada estructura etaria de la región, producto del estado avanzado, aunque aún en desarrollo, de la transición demográfica, favorece el contacto intergeneracional y la conformación de hogares multigeneracionales. A esto se suman los niveles más altos de fecundidad del pasado (que se hacen sentir en la actualidad en las cohortes de personas mayores, que tienen, en promedio, tres o más hijos y una cantidad promedio no menor de nietos). También se añade el aumento de la esperanza de vida, lo que puede traducirse en corresidencia intergeneracional familiar. Por su parte, las desigualdades reproductivas que aún se observan en la región, y que implican una fecundidad todavía más alta entre los grupos pobres, eleva la probabilidad de corresidencia intergeneracional en dichos grupos. La fecundidad adolescente, que sigue siendo alta, también aumenta las probabilidades de corresidencia intergeneracional, pues, ante la falta de recursos, las jóvenes (eventualmente con su pareja) permanecen con el bebé en el hogar de sus padres (o suegros) o de sus abuelos (Rodríguez y Cobos, 2014).

A lo mencionado se agregan otros factores, ya que la demografía es solo una de las fuerzas que influyen en la conformación de los arreglos familiares. Entre estos se encuentran los socioeconómicos y culturales, dos factores que en la región tienden a reforzar la corresidencia intergeneracional. Las condiciones socioeconómicas desmedradas de una parte importante de las personas mayores empujan a la conformación de arreglos familiares multigeneracionales como estrategia - o única opción- de sobrevivencia. Además, las pautas culturales de la región - de lazos familiares fuertes (Ullmann, Maldonado y Nieves, 2014) — son más bien favorables a los hogares familiares multigeneracionales, por lo que son frecuentes los hogares donde, muchas veces en espacios cerrados y pequeños, conviven niños, adultos y personas mayores.

En general, América Latina y el Caribe tiende a alinearse con el resto de las regiones en desarrollo. Con todo, en materia de arreglos familiares intergeneracionales, se sitúa más bien en una posición intermedia entre Asia y África, por una parte, y Europa y América del Norte, por la otra. Como se aprecia claramente en el gráfico 5, en África y Asia más del 60\% de las personas mayores residen con uno o más de sus hijos, mientras que ese porcentaje no supera el 20\% en Europa o América del Norte. En América Latina y el Caribe ese valor es del 52\%, algo menos que el promedio mundial (53\%).

Por el momento hay poca evidencia directa y sólida respecto del papel que juega la corresidencia familiar, pues la epidemia está en curso y las investigaciones requerirán más tiempo para llegar a resultados representativos. Con todo, algunos demógrafos de Europa vinculan los altos niveles de corresidencia familiar intergeneracional en los países del sur de Europa con la magnitud y gravedad sobresalientes del COVID-19 en esos territorios, en particular con la mortalidad y el colapso de los sistemas de urgencia (Balbo, Billari y Melegaro, 2020). Dado que América Latina y el Caribe comparte la matriz cultural de lazos familiares fuertes del sur de Europa y además suma las presiones económicas y la falta de protección social en la vejez, dos factores que incentivan u obligan a la corresidencia familiar intergeneracional, es esperable que los índices de corresidencia entre diferentes generaciones sean elevados y mayores entre los grupos de menos recursos, lo que puede ser un factor adicional de riesgo de contagio del COVID-19. 
Gráfico 5

Mundo y regiones: distribución de personas de 60 años y más por tipo de arreglo del hogar, alrededor de 1990 y 2010 (En porcentajes)

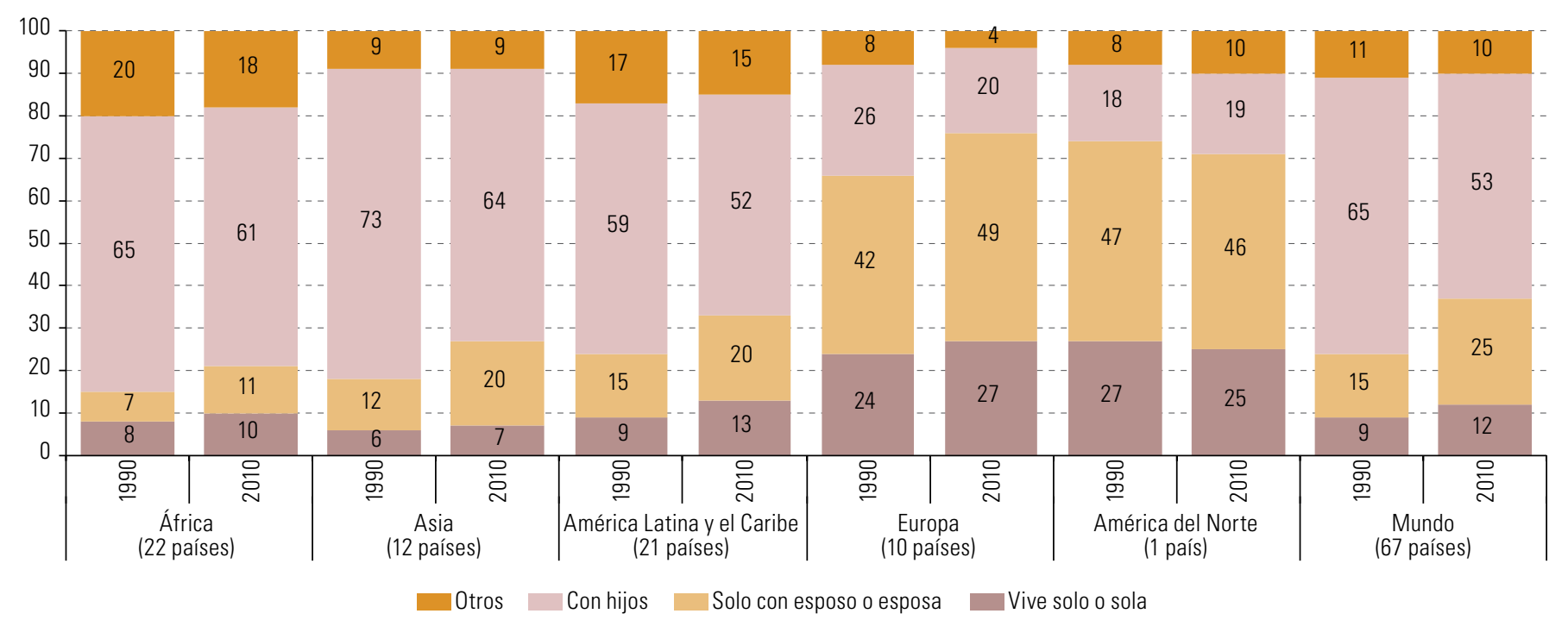

Fuente: Naciones Unidas, Living Arrangements of Older Persons: A Report on an Expanded International Dataset (ST/ESA/SER.A/407), Nueva York, 2017.

A modo de ejemplo, en el cuadro 4 se sistematiza información de los censos (o encuestas intercensales) levantados recientemente en cinco países de la región (México, 2015; Chile y Perú, 2017; Colombia y Guatemala, 2018) y, por ende, representativos de los patrones actuales de corresidencia intergeneracional (porque esta es estructural y tarda en cambiar). Los datos se enfocan en los arreglos residenciales de las personas de 60 años y más, analizando el tamaño de los hogares y su composición.

\section{Cuadro 4}

América Latina y el Caribe (5 países): hogares particulares con personas mayores, según número de personas en el hogar y personas de 60 años y más por arreglos domiciliarios

(En porcentajes)

\begin{tabular}{|c|c|c|c|c|c|c|c|c|c|}
\hline \multirow{3}{*}{$\begin{array}{l}\text { País/año } \\
\text { del censo }\end{array}$} & \multicolumn{4}{|c|}{ Panel A - Nivel de envejecimiento doméstico } & \multicolumn{5}{|c|}{ Panel B - Nivel de envejecimiento demográfico } \\
\hline & \multirow{2}{*}{$\begin{array}{l}\text { Hogares } \\
\text { particulares con } \\
\text { personas de } \\
60 \text { años y más }\end{array}$} & \multicolumn{3}{|c|}{$\begin{array}{l}\text { Número de personas } \\
\text { en el hogar }\end{array}$} & \multirow{2}{*}{$\begin{array}{l}\text { Personas } \\
\text { de } \\
60 \text { años } \\
\text { y más }\end{array}$} & \multirow[b]{2}{*}{ Vive sola } & \multicolumn{3}{|c|}{ Vive con otras personas } \\
\hline & & $1-2$ & $3-4$ & 5 o más & & & $\begin{array}{c}\text { Todas } \\
\text { personas } \\
\text { mayores }\end{array}$ & $\begin{array}{l}\text { Otras edades } \\
\text { sin niños de } \\
0 \text { a } 14 \text { años }\end{array}$ & $\begin{array}{c}\text { Otras edades } \\
\text { con niños } \\
\text { de } 0 \text { a } 14 \\
\text { años y otros }\end{array}$ \\
\hline Colombia, 2018 & 30,4 & 46,6 & 34,9 & 18,5 & 13,4 & 14,2 & 19,8 & 44,4 & 21,7 \\
\hline Guatemala, 2018 & 27,0 & 29,8 & 29,1 & 41,1 & 8,1 & 8,0 & 14,5 & 35,7 & 41,9 \\
\hline $\begin{array}{l}\text { Perú, } 2017 \\
\text { (Viviendas) }\end{array}$ & 30,4 & 42,4 & 29,8 & 27,8 & 11,9 & 14,2 & 17,5 & 39,2 & 29,1 \\
\hline Chile, 2017 & 35,6 & 50,7 & 32,5 & 16,8 & 16,2 & 14,5 & 24,5 & 41,4 & 19,6 \\
\hline México, 2015 & 28,4 & 42,3 & 31,0 & 26,7 & 10,4 & 11,1 & 21,3 & 39,6 & 28,0 \\
\hline
\end{tabular}

Fuente: Comisión Económica para América Latina y el Caribe (CEPAL), sobre la base de censos de población y vivienda de los respectivos países. 
La prevalencia de hogares con personas mayores, con miembros particularmente sensibles en caso de contagio, se va del el 27,0\% en Guatemala y el 35,6\% en Chile (véase el panel A del cuadro 4). Si bien se trata de extremos predecibles, por ser Guatemala el país menos avanzado en la transición demográfica y Chile el más avanzado, la diferencia entre ellos no parece tan abultada como cabía esperar y las magnitudes sugieren que alrededor de 1 de cada 3 hogares de la región incluye al menos una persona mayor, por lo que serían hogares de riesgo especial. En todos los países, salvo Guatemala, los hogares en los que viven personas mayores son más bien pequeños, pues predominan ampliamente aquellos con 1 o 2 personas, aunque en todos los países, con excepción de Chile, la mayoría de los hogares con personas mayores tienen 3 personas o más, lo que aumenta la probabilidad de que sean intergeneracionales.

La información del panel B del cuadro 4 es más atinente aún al tema analizado, pues la unidad de referencia son personas y no hogares, y el contexto de residencia corresponde a diferentes opciones de arreglos intergeneracionales. En línea con la descripción realizada anteriormente del proceso de envejecimiento en la región y el mundo, se muestra que el envejecimiento demográfico está más avanzado en Chile, que duplica a Guatemala (el país menos envejecido de los cinco examinados). Si bien se trata de cifras no menores, y ciertamente más altas que las de hace algunas décadas, aún están lejos de los niveles de los países desarrollados, que en algunos casos se acercan al 30\% de la población de 60 años y más (Naciones Unidas, 2019a).

Justamente por los indicios de que los niños pueden ser un vector importante y silencioso de transmisión del virus, en el panel B del cuadro 4 se segmentan los hogares multigeneracionales entre aquellos donde hay niños y aquellos donde no los hay. Si bien en todos los países, salvo Guatemala, el grupo de hogares multigeneracionales donde hay niños es minoritario, un mínimo de un $20 \%$ de las personas mayores reside con niños, por lo que su salud puede depender críticamente de las acciones de distanciamiento social dirigidas a los menores.

Por otra parte, los resultados nacionales tienen expresiones territoriales y sociales muy diversas en cada país. A escala territorial, el nivel de envejecimiento y las modalidades de corresidencia en que viven las personas mayores cambian significativamente según se trate, entre otros, de zonas urbanas o rurales, municipios centrales o periféricos de áreas metropolitanas, o regiones de mayor o menor desarrollo económico y social. Según el XII Censo Nacional de Población y VII Censo Nacional de Vivienda de 2018 de Guatemala, el nivel de envejecimiento, medido mediante el porcentaje de personas mayores en la población total, variaba entre un $4,6 \%$ en el municipio menos envejecido (Chisec) y un $14,7 \%$ en el más envejecido (Jerez) (véase el mapa 2). Cada país debería hacer un análisis detallado de estos patrones territoriales con los datos censales.

b) Personas mayores en hogares unipersonales

Las personas mayores que viven solas constituyen un grupo de riesgo ante la excepcionalidad que se vive a causa de la pandemia, pues pueden llegar a verse afectadas de manera desproporcionada por las medidas de distanciamiento físico. Pueden enfrentar barreras para obtener información precisa, alimentos, medicamentos y otros suministros esenciales durante las condiciones de cuarentena (Lloyd-Sherlock y otros, 2020). Además, los períodos prolongados de aislamiento podrían tener un efecto grave en la salud mental y provocar que los sentimientos de soledad no deseada y sus efectos vayan en aumento (OMS, 2020b). No obstante, pueden estar menos expuestas al riesgo de contagio al no compartir el hogar con otras personas que quizás tengan una mayor probabilidad de contagio al tener que salir a trabajar o a realizar compras para la subsistencia diaria.

En las últimas décadas, los resultados proporcionados por los censos en la mayoría de los países de la región revelan un notorio aumento de la cantidad de hogares de personas mayores que viven solas. En un estudio comparativo entre regiones, donde se utiliza una base de datos creada por las Naciones Unidas (2019c), se constata que la región presenta una situación intermedia en comparación con otras regiones. La mayoría de los países de América Latina y el Caribe se encuentran en una posición intermedia, a excepción de la Argentina y el Uruguay, donde hasta el 21,2\% y el 26,7\% de la población mayor, respectivamente, vivía sola (Naciones Unidas, 2019d, pág. 2). 
Mapa 2

Guatemala: población de 60 años y más por municipios, censos de 2018

(En porcentajes)

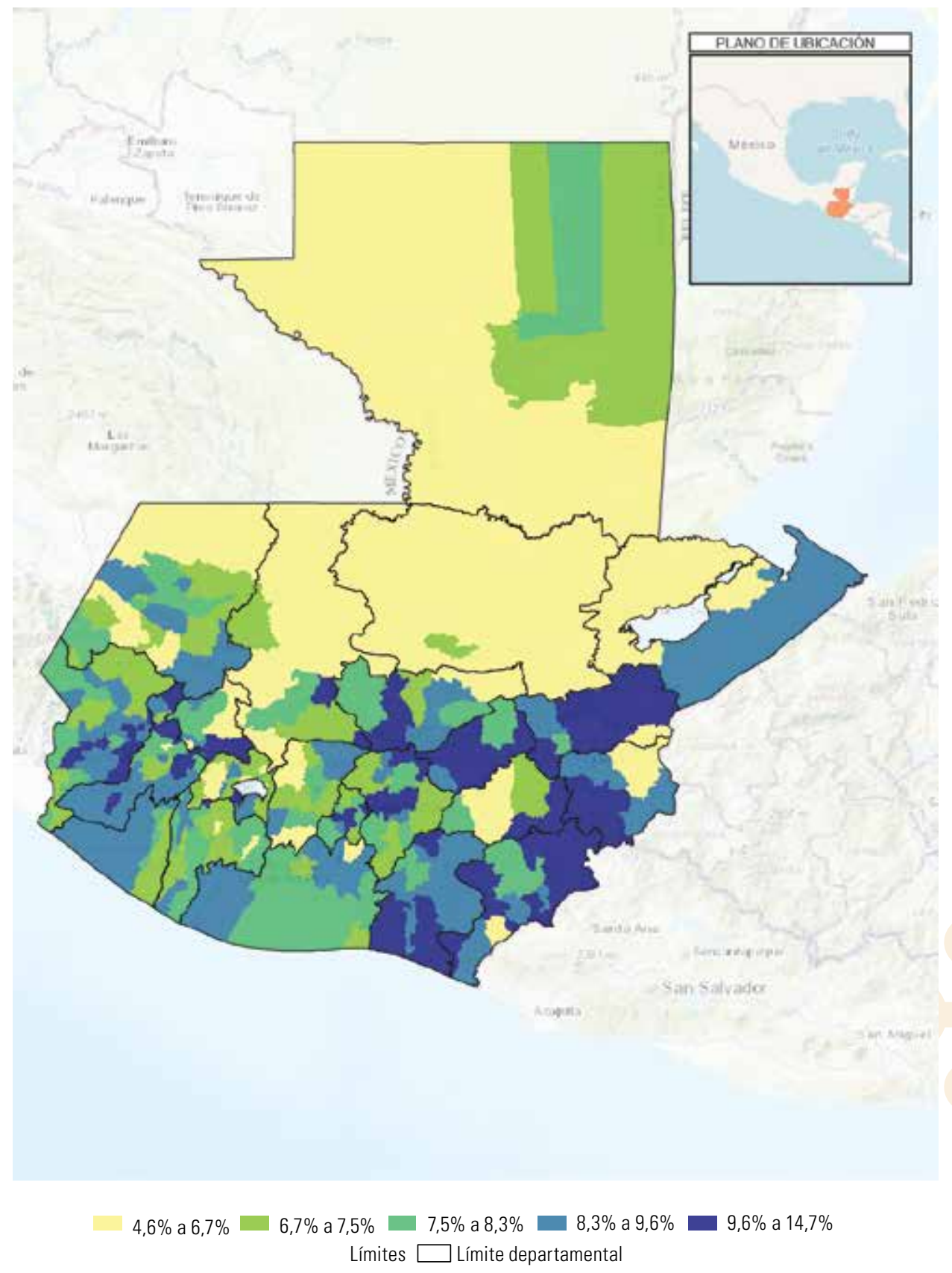

Fuente: Comisión Económica para América Latina y el Caribe (CEPAL), sobre la base de Instituto Nacional de Estadística (INE), XII Censo Nacional de Población y VII Censo Nacional de Vivienda, Ciudad de Guatemala, 2018 [en línea] https://www.censopoblacion.gt/explorador. 
Los datos de los censos recientes de Colombia (2018), Guatemala (2018) y el Perú (2017), así como de la encuesta intercensal de México (2015), muestran que la proporción de personas de 60 años y más que viven solas varía entre un $8 \%$ en Guatemala, un 11\% en México y alrededor del 14\% en Chile, Colombia y el Perú (véase el gráfico 6). Es interesante observar también el porcentaje de personas mayores de 60 años que viven con otras personas mayores exclusivamente, con cifras que varían de un mínimo del 14,5\% en Guatemala a un máximo del 24,5\% en Chile.

\section{Gráfico 6}

América Latina (5 países): personas de 60 años y más por arreglos domiciliarios, censos recientes (En porcentajes)

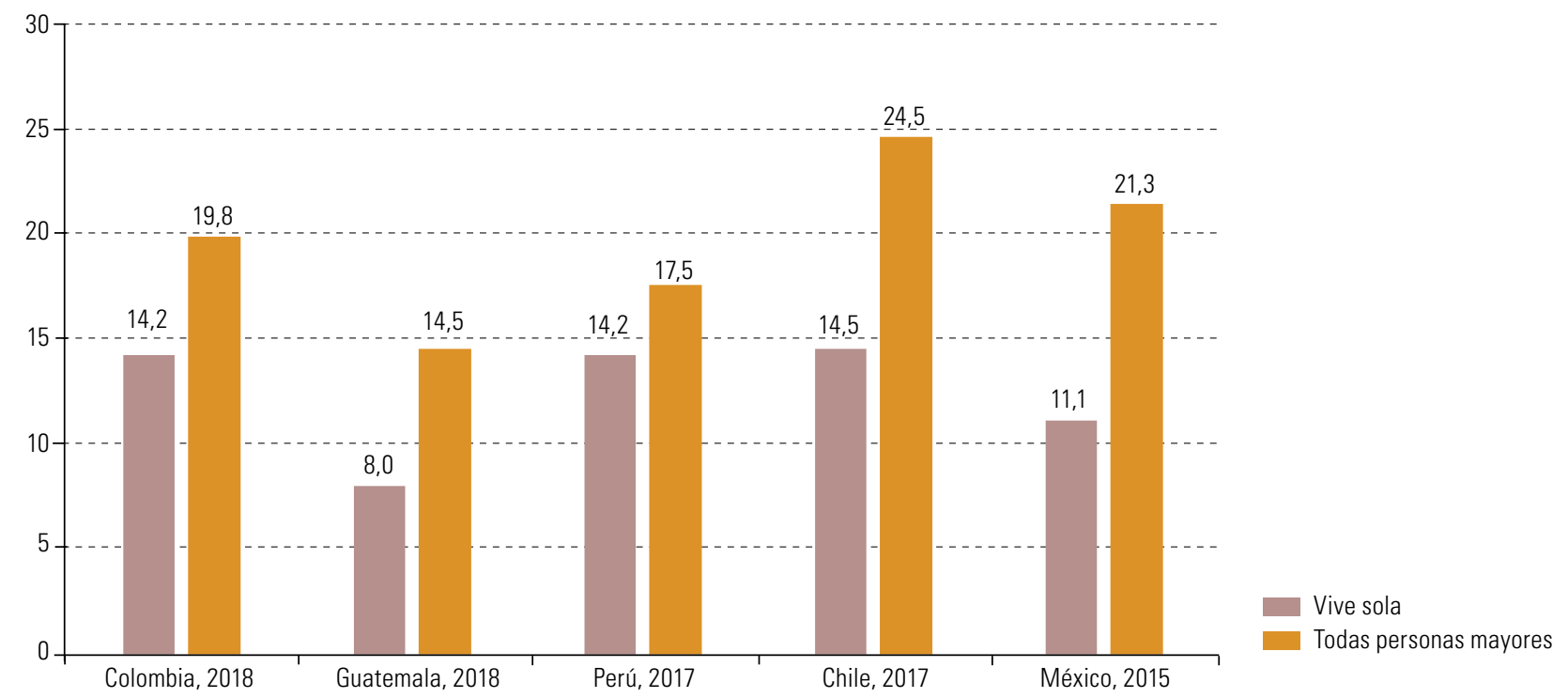

Fuente: Comisión Económica para América Latina y el Caribe (CEPAL), sobre la base de microdatos censales.

La medida prioritaria 20 del Consenso de Montevideo sobre Población y Desarrollo hace especial mención a las personas que viven solas y no cuentan con redes de contención, dado que son susceptibles de discriminación. En consecuencia, se exhorta a los países a desarrollar, en todos los niveles de administración, políticas tendientes a garantizar la calidad de vida, el desarrollo de las potencialidades y la participación plena de las personas mayores, atendiendo las necesidades de estímulos intelectuales, afectivos y físicos.

Ante las medidas de aislamiento social implementadas a raíz de la pandemia, las personas mayores que viven solas o con otra persona mayor demandan acciones específicas, como el llamado que ha hecho la Comisión Interamericana de Derechos Humanos (CIDH, 2020) para que los Estados consideren "el balance que debe existir entre la protección ante el COVID-19 y la necesidad particular de las personas mayores de conexión con sus familiares, y facilitar medios de comunicación telefónica o por internet, a fin de evitar su deterioro emocional [...] Asimismo, las medidas adoptadas deben identificar y eliminar obstáculos y barreras para el acceso de las personas mayores a su abastecimiento, servicios públicos, cuidados, información y comunicación durante el aislamiento. La Comisión resalta también la necesidad de cooperación entre los Estados y las empresas privadas que brindan servicios y bienes esenciales para facilitar el acceso prioritario a las personas mayores con horarios especiales para su atención, como se viene haciendo en varios supermercados y bancos de la región". 


\section{c) Personas mayores institucionalizadas}

Las personas mayores que viven en centros de atención a largo plazo, como hogares de ancianos y centros de rehabilitación, son particularmente vulnerables a las infecciones y los resultados adversos del COVID-19. Según estudios preliminares realizados a nivel internacional, el número de muertes en estos hogares representó entre el 19\% y el $62 \%$ de todas las muertes por COVID-19 en países de Europa y Asia (Comas-Herrera y otros, 2020, pág. 2). Por otra parte, la propagación del virus puede dificultar el tratamiento de las enfermedades crónicas que estas personas padezcan, exponiéndolas a una muerte anticipada.

La población de personas mayores que vive en residencias de cuidados de largo plazo aún representa una pequeña fracción en los países de la región, aunque es cada vez mayor en aquellos que se encuentran en una etapa más avanzada del proceso de envejecimiento poblacional. Los datos censales con fechas cercanas a 2010, provenientes de los registros de viviendas colectivas, muestran que en la mayoría de los países apenas el 0,25\% de la población vivía en este tipo de residencias (véase el gráfico 7). La excepción son Chile y el Uruguay, que presentan una estructura por edad más envejecida respecto de los demás países analizados. En valores absolutos, alrededor de 166.000 personas mayores vivían en estas instituciones, y no se aprecian diferencias significativas en la distribución por sexo (salvo en el Uruguay, donde el número de mujeres supera al de hombres).

\section{Gráfico 7}

América Latina y el Caribe: personas mayores que viven en residencias de largo plazo por sexo, censos con fechas cercanas a 2010 (En porcentajes)

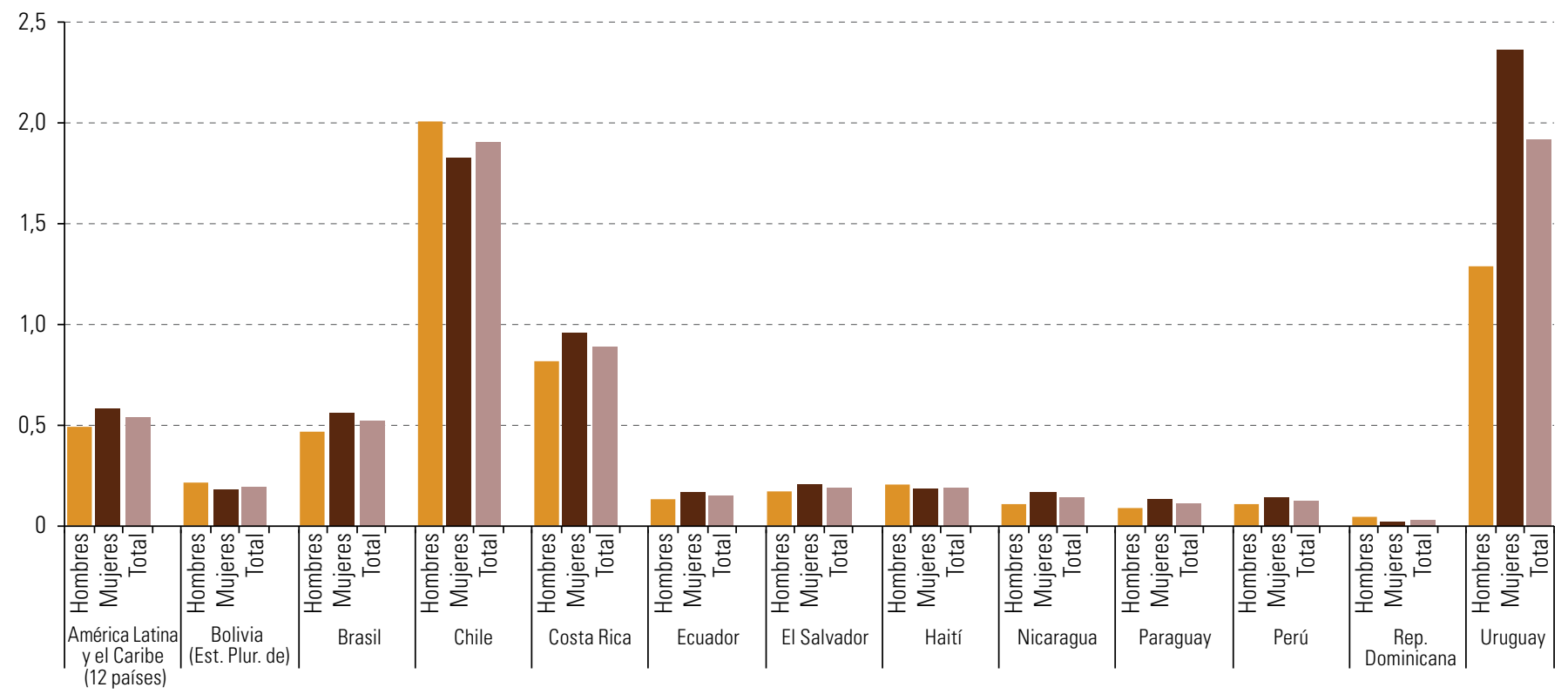

Fuente: Banco Interamericano de Desarrollo (BID), "Indicadores: panorama de envejecimiento y atención a la dependencia", 2020 [en línea] https://www.iadb.org/es/panorama/indicadores; S. Ruggles y otros, "Integrated Public Use Microdata Series: Version 7.0 [dataset]", Minneapolis, Universidad de Minnesota, 2017 [en línea] https://ipums.org/projects/ipums-usa/d010.v7.0.

Cabe mencionar que las medidas de distanciamiento físico que restringen las visitas y las actividades grupales en los centros de larga estadía pueden afectar negativamente la salud física y mental, así como el bienestar de las personas mayores, sobre todo aquellas con deterioro cognitivo o demencia, y que dependen mucho de la atención. En el recuadro 2 se mencionan con mayor detalle los impactos en la salud mental de las personas mayores y las medidas que se sugieren a nivel internacional para mitigarlos. Si bien en general las medidas son para las personas mayores que residen en hogares particulares, se recogen también algunas directrices para personas mayores institucionalizadas. 
Recuadro 2

Salud mental de las personas mayores y COVID-19

La Organización Mundial de la Salud (OMS) ha planteado la necesidad de implementar acciones oportunas para disminuir el estrés y otros efectos psicológicos en la población a causa de factores específicos vinculados al brote de COVID-19. Entre las personas mayores se han constatado efectos psicológicos negativos (como confusión, enojo, agotamiento, desapego, ansiedad, deterioro del desempeño y resistencia a realizar actividades de la vida diaria), que pueden llegar incluso al trastorno de estrés postraumático y la depresión.

El riesgo de estar infectado e infectar a otros, o confundir síntomas de otros problemas de salud con los del COVID-19 debido a la imposibilidad de asistir a los controles médicos regulares a causa de la pandemia, son factores que también influyen sobre el riesgo de deterioro de la salud física y mental de las personas mayores. Otro factor es la implementación de las medidas de cuarentena en casi todos los países de la región, que resultan particularmente restrictivas para las personas mayores, en especial para las de 75 años y más. Este confinamiento obligatorio en el hogar tiene consecuencias en la salud mental de las personas mayores, pues afecta la comunicación con sus familiares o amigos, debilita sus redes de apoyo social y provoca un cambio en las rutinas de las actividades que realizan a diario. La sensación de inseguridad ante el contagio se acentúa con los sentimientos de soledad y abandono al no poder recibir la visita de su familia o salir a realizar sus actividades en la comunidad (por ejemplo, reunirse con sus pares en organizaciones de personas mayores). A esto se agregan los problemas que experimentan con el abastecimiento de suministros básicos o medicamentos para su subsistencia al no poder salir de compras, lo que, sumado a los problemas económicos para satisfacer sus necesidades vitales y de servicios básicos, les va generando angustia y preocupación.

La salud emocional de las personas mayores es clave para que puedan realizar sus cuidados generales, tomar decisiones adecuadas y llevar adelante su vida en un contexto adverso prolongado.

Entre las medidas que se deben adoptar se destaca la importancia de que los equipos multidisciplinarios de salud mental brinden apoyo a los pacientes mayores, proporcionen una comunicación clara con actualizaciones periódicas y precisas sobre la situación, ofrezcan consejería o tratamientos psiquiátricos oportunos a quienes presentan problemas de salud mental más graves y brinden a la población mensajes y orientaciones respecto de cómo proteger su salud mental mediante acciones que reduzcan el estrés, la angustia y el aburrimiento, tomando en cuenta sus intereses y su situación socioeconómica.

Las medidas específicas para las personas mayores que viven solas incluyen: asegurarse de contar con todos los medicamentos que necesiten si padecen alguna enfermedad; activar sus contactos sociales para que, de ser necesario, les brinden ayuda; estar preparados y saber de antemano dónde y cómo obtener ayuda si la necesitan (como llamar a un taxi, recibir comida o solicitar atención médica); aprender ejercicios físicos simples que puedan realizar a diario en su casa para mantener la movilidad y reducir el aburrimiento; mantener la rutina y los horarios habituales, en la medida de lo posible, o poner en práctica nuevas rutinas u horarios (esto incluye ejercicio regular, limpieza, tareas domésticas diarias y otras actividades como cantar y bailar); mantener un contacto regular con sus seres queridos a través de los medios que tenga disponibles; alentar a sus familiares o amigos a llamarlos con regularidad y que les enseñen cómo utilizar las videollamadas, y aprender a utilizar los equipos de protección personal (como el tapabocas).

Fuente: Comisión Económica para América Latina y el Caribe (CEPAL), sobre la base de Infobae, "Cómo preservar la salud mental de los adultos mayores durante la cuarentena", Buenos Aires, 26 de mayo de 2020 [en línea] https://www.infobae.com/tendencias/2020/05/26/ como-preservar-la-salud-mental-de-los-adultos-mayores-durante-la-cuarentena/; Centro para el Control y la Prevención de Enfermedades (CDC), "Personas con discapacidad", 11 de septiembre de 2020 [en línea] https://espanol.cdc.gov/coronavirus/2019-ncov/need-extraprecautions/people-with-disabilities.html.

Otro aspecto para destacar sobre las instituciones de larga permanencia es la vulnerabilidad a la que está expuesto tanto el personal que brinda los cuidados como los trabajadores de salud que atienden a las personas mayores, por la mayor exposición al riesgo y la probabilidad de ser vector de contagio (UNFPA, 2020). El estrés físico y psicológico del trabajo en tiempos de pandemia debe enfrentarse con medidas adecuadas de protección para no poner en riesgo a todos, incluida la propia población institucionalizada.

Para garantizar los derechos de la población mayor, así como para proteger a sus cuidadores, es esencial identificar prontamente las contaminaciones, realizar pruebas y tomar medidas de aislamiento, con cuidado permanente (OMS, 2020c). En situaciones de detección de casos es esencial entrenar y aumentar el personal que brinda los cuidados para contener el contagio masivo (Huenchuan, 2020a). También es fundamental evitar transferir a la población mayor a entornos alternativos, siempre que sea posible, como solución a los problemas de personal (CDC, 2020). 


\section{Acceso de las personas mayores a servicios básicos: agua y saneamiento}

Además del aislamiento personal, las principales formas de evitar el contagio ante el brote de COVID-19, que se propaga por un virus transmisible, principalmente por gotas respiratorias y contacto directo, son las medidas de higiene respiratoria y de higiene manos. Las medidas recomendadas por la OMS incluyen el uso de mascarillas, pero se refieren principalmente al lavado de manos con agua y jabón o al uso de gel a base de alcohol (OMS, 2020d). El agua también es esencial para la limpieza y desinfección de objetos y superficies que se tocan con frecuencia, ya que el contacto directo con el virus en estas superficies es uno de los modos de transmisión.

El agua y el saneamiento, que son cruciales para la vida, la salud y la higiene, juegan un papel clave en la contención de la enfermedad. En el caso de las personas mayores, el acceso a estos servicios tiene carácter diferencial, puesto que no son un grupo homogéneo y existen particularidades según área urbana y rural, condición de salud, grupo socioeconómico y demás. Si bien las ciudades presentan mejores indicadores de acceso a los servicios de agua y saneamiento, en las grandes ciudades persisten enormes desigualdades socioterritoriales, en particular entre las poblaciones más pobres. Los tugurios, por ejemplo, son asentamientos precarios que no cuentan con acceso a agua potable y saneamiento. La mayoría de ellos recibe el abastecimiento de agua potable esporádicamente mediante un camión aljibe o cuenta con una llave de agua potable en el terreno para satisfacer la necesidad de un importante número de familias. En el contexto actual de pandemia, los asentamientos precarios son lugares donde los brotes de contagio del COVID-19 pueden ser muy recurrentes, pues la tríada de altos niveles de hacinamiento y falta de acceso a agua potable y saneamiento acentúa las probabilidades de contagio y propagación del virus.

Los instrumentos internacionales reconocen el derecho al agua potable y el saneamiento como un derecho humano esencial para el pleno disfrute de la vida y de todos los derechos humanos (Huenchuan, 2018). La Agenda 2030 para el Desarrollo Sostenible, particularmente en el Objetivo 6, se propone garantizar la disponibilidad de agua y su gestión sostenible y el saneamiento para todos, incluidas las personas mayores. En este sentido, el informe de monitoreo de los Objetivos del Desarrollo Sostenible advierte que la adopción de medidas inmediatas de mejora en materia de agua, saneamiento e higiene para todos es fundamental para prevenir la infección y contener su propagación (Naciones Unidas, 2020a, pág. 10).

Asimismo, en la medida prioritaria 77 del capítulo G del Consenso de Montevideo sobre Población y Desarrollo se menciona la necesidad de promover el desarrollo y el bienestar de las personas de todos los territorios, sin ningún tipo de discriminación, incluido el pleno acceso a los servicios sociales básicos. El primer informe regional sobre la implementación del Consenso de Montevideo sobre Población y Desarrollo daba cuenta de una continua mejora en las acciones implementadas en la infraestructura de provisión de agua y saneamiento a la población en la región (CEPAL, 2019a). Sin embargo, el informe llama la atención sobre grandes brechas que siguen la misma estructura de las desigualdades de la región. En áreas rurales, el acceso al agua potable es deficiente. En los bolsones de pobreza urbanos, con una enorme segregación e inequidad, la falta de disponibilidad de viviendas de calidad es causa de un acceso deficiente a servicios de agua y saneamiento para los grupos de población en situación de mayor vulnerabilidad. Entre estos grupos, las personas mayores presentan aún más vulnerabilidades por sus condiciones de salud y posibles fragilidades

En el recuadro 3 se mencionan con mayor detalle los artículos de los instrumentos internacionales que abordan la importancia de vivir en un ambiente saludable, con una calidad de vida adecuada para las personas mayores, entendiéndose que el acceso a agua potable y saneamiento es un derecho esencial para vivir de manera adecuada, situación que en este contexto de pandemia se hace mucho más evidente, tal como ya se ha indicado. 
Recuadro 3

Artículos de los instrumentos internacionales que abordan la importancia de vivir en un ambiente saludable y con una calidad de vida adecuada para las personas mayores

\section{Artículo 25 de la Convención Interamericana sobre la Protección de los Derechos Humanos de las Personas Mayores} Derecho a un medio ambiente sano

La persona mayor tiene derecho a vivir en un medio ambiente sano y a contar con servicios públicos básicos, a tal fin los Estados Parte adoptarán las medidas pertinentes para salvaguardar y promover el ejercicio de este derecho, entre ellas:

a) Fomentar el desarrollo pleno de la persona mayor en armonía con la naturaleza.

b) Garantizar el acceso de la persona mayor en condiciones de igualdad a servicios públicos básicos de agua potable y saneamiento, entre otros

Carta de San José sobre los Derechos de las Personas Mayores de América Latina y el Caribe

(Adoptada en la Tercera Conferencia Regional Intergubernamental sobre Envejecimiento en América Latina y el Caribe, San José, 8 a 11 de mayo de 2012)

10. Trabajaremos por mejorar las condiciones de vivienda y del entorno de las personas mayores para fortalecer su autonomía e independencia, a través de:

a. Realizar los mayores esfuerzos para que las personas mayores disfruten de una vivienda adecuada y tengan alta prioridad en la asignación de viviendas o tierras, en especial en situaciones derivadas de crisis, emergencia, desplazamiento o desalojo forzado,

b. Propiciar que las personas mayores vivan en un entorno seguro y saludable, incluido el acceso a servicios y facilidades de transporte,

c. Crear y reacondicionar espacios públicos amigables y seguros, garantizando, mediante la eliminación de barreras arquitectónicas, la accesibilidad de las personas mayores.

Fuente: Organización de los Estados Americanos (OEA), Convención Interamericana sobre la Protección de los Derechos Humanos de las Personas Mayores, Washington, D.C., 2015; Comisión Económica para América Latina y el Caribe (CEPAL), Carta de San José sobre los Derechos de las Personas Mayores de América Latina y el Caribe (LC/G.2537), Santiago, 2012.

Los datos censales e intercensales más recientes en cinco países muestran que aquellos con procesos más avanzados de envejecimiento y urbanización son los que presentan mayores porcentajes de acceso a agua y saneamiento adecuados (véase el gráfico 8). Sin embargo, los porcentajes de personas mayores que viven en hogares sin acceso adecuado a agua pueden ir de un mínimo del $4 \%$ del total de personas mayores en el país, como en el caso de Chile, a un máximo del 16\%, como en el caso de Guatemala. Las áreas rurales de Colombia y Guatemala son las que cuentan con más personas mayores en situación de vulnerabilidad en relación con el acceso al agua, un insumo que es esencial para la contención del contagio del COVID-19.

El panorama en cuanto al acceso a servicios de saneamiento adecuados en las viviendas presenta una situación bastante más preocupante para las personas mayores, principalmente en el área rural (véase el gráfico 9). Los datos de los censos más recientes muestran que casi el 30\% de las personas mayores que viven en el área rural de Guatemala no tienen acceso adecuado a saneamiento, mientras que en el Perú la cifra llega a casi el 13\% y Colombia y México registran los porcentajes más bajos. Se sabe que, en la mayoría de estos países, la situación es sumamente heterogénea a nivel subnacional, con áreas urbanas muy segregadas y áreas rurales muy pobres. Por tanto, es esencial disponer de información detallada para identificar dónde viven y cuántas son las personas que necesitan que se implementen acciones que les permitan asegurar la disponibilidad de la infraestructura necesaria de acceso a agua y saneamiento como un derecho, y de manera aún más urgente en una situación sanitaria en la cual el acceso a la higiene adecuada puede significar la diferencia entre la vida y la muerte.

Es importante señalar que los indicadores de acceso adecuado a agua y saneamiento, tomados de censos o encuestas, por lo general solo captan información sobre la forma de acceso en las viviendas, pero no miden la calidad del agua o la frecuencia diaria con que llega a los hogares. Tampoco informan si hay tratamiento adecuado del saneamiento 
antes de volver a la naturaleza, muchas veces contaminando sistemas hídricos que más adelante serán la fuente del agua de muchas personas. Debe haber orientaciones firmes en la política pública en relación con la provisión de servicios de agua y saneamiento, que son parte esencial de la salud pública, y un derecho humano fundamental, particularmente en contextos de pandemia.

\section{Gráfico 8}

América Latina (5 países): personas de 60 años y más según acceso a servicios de agua potable, por áreas urbanas y rurales, censos recientes

(En porcentajes)

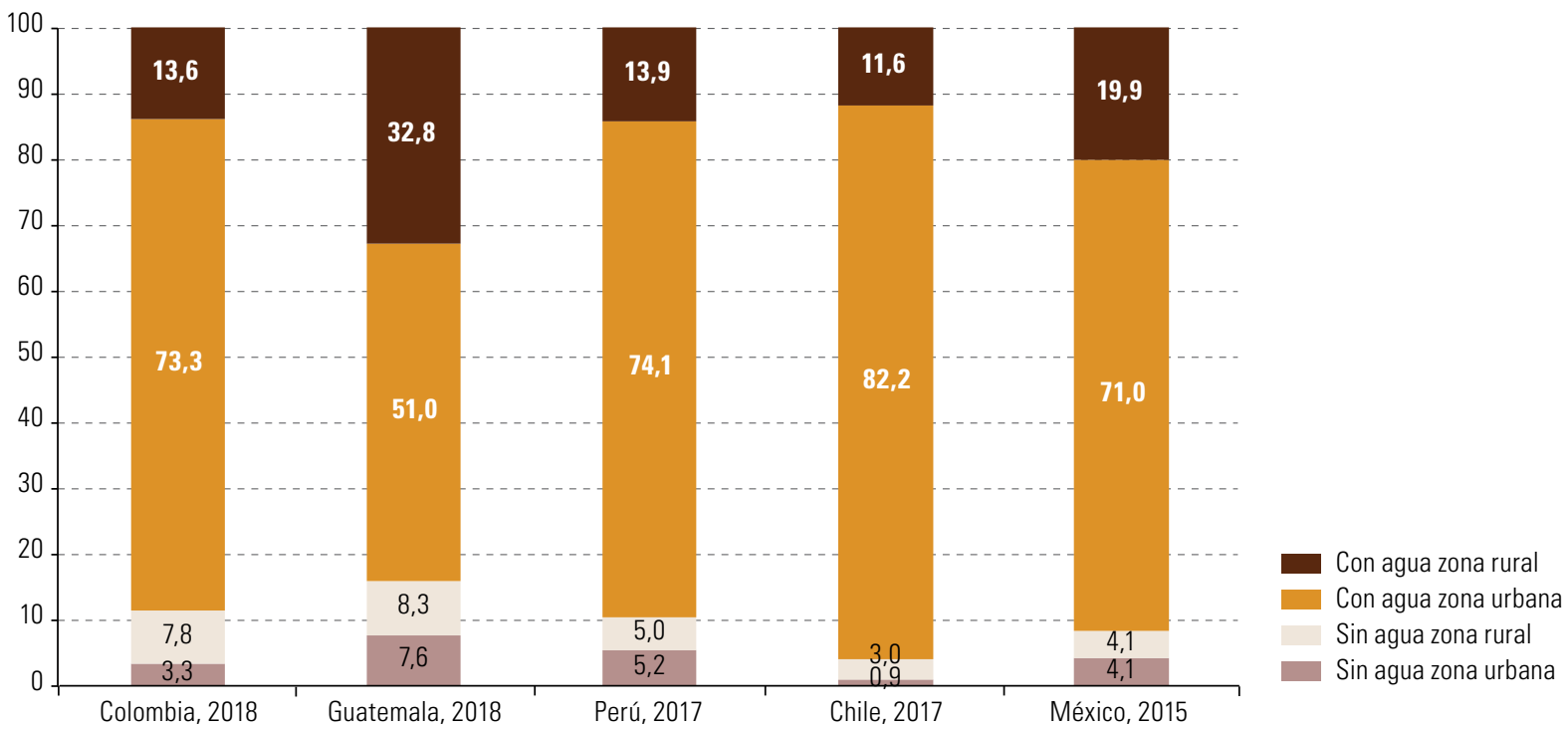

Fuente: Comisión Económica para América Latina y el Caribe (CEPAL), sobre la base de microdatos censales.

Nota: El total no incluye las categorías No aplica (que, dependiendo del censo, se refiere a las personas mayores en viviendas colectivas o sin vivienda), No especificado, No informa, No prepara alimentos o no declara, casas en arriendo, vacaciones, moradores ausentes o una suma de varias de estas subcategorías.

\section{Gráfico 9}

América Latina (4 países): personas de 60 años y más según acceso del hogar a servicios de saneamiento, por áreas urbanas y rurales, censos recientes

(En porcentajes)

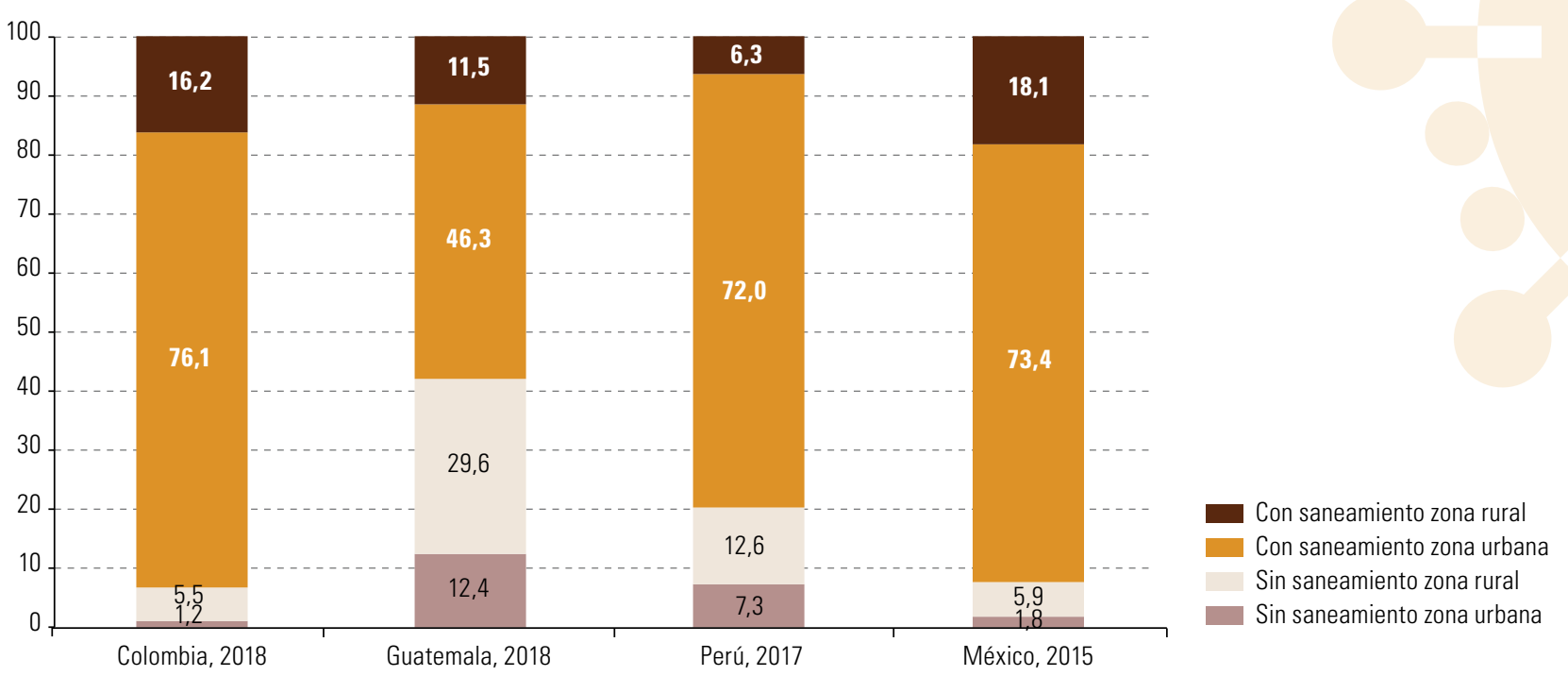

Fuente: Comisión Económica para América Latina y el Caribe (CEPAL), sobre la base de microdatos censales.

Nota: El total no incluye las categorías "No aplica" (que, dependiendo del censo, se refiere a las personas mayores en viviendas colectivas o sin vivienda), "No especificadơ" o una suma de varias de estas subcategorías. 


\section{La necesaria expansión y mejora de los sistemas de protección social con foco en las personas mayores}

El devastador impacto social y económico del COVID-19 exige una respuesta urgente para proteger los derechos humanos y la dignidad de las personas mayores. La protección social, entendida como el conjunto de intervenciones de entes públicos y privados que buscan aliviar a los hogares y a las personas de la carga que suponen ciertos riesgos y necesidades que surgen a lo largo de la vida y construir resiliencia frente a sucesos inesperados o inevitables (accidente, enfermedad, pérdida del empleo y desastres naturales, entre otros), está destinada a integrar una variedad de acciones orientadas a construir sociedades más justas e inclusivas, y a garantizar niveles mínimos de vida (Arenas de Mesa, 2019).

La importancia de mejorar y ampliar el acceso a los sistemas de protección social para que respondan efectivamente a las necesidades de las personas mayores se ha reconocido en varios instrumentos internacionales, como el artículo 17 de la Convención Interamericana sobre la Protección de los Derechos Humanos de las Personas Mayores (OEA, 2015), la Carta de San José sobre los Derechos de las Personas Mayores de América Latina y el Caribe ${ }^{5}$, las medidas prioritarias 26 y la 31 del Consenso de Montevideo sobre Población y Desarrollo ${ }^{6}$, la meta 1.3 de los Objetivos de Desarrollo Sostenible (ODS) y la Declaración de Asunción ${ }^{8}$. La vulneración de derechos en los temas de protección social (salud, ingresos, pensiones) ya existía antes de la pandemia en la región, que se caracteriza por ser la más desigual del mundo, y si no se abordan las causas estructurales que han dejado atrás a las personas mayores y vulnerables, como los más pobres, las mujeres mayores y los que presentan mayor grado de dependencia, en particular en la situación de crisis sanitaria, se corre el riesgo de que la desprotección se acentúe.

Frente a los cambios demográficos suscitados en la región, donde se destacan el proceso de envejecimiento demográfico, el aumento de la esperanza de vida, la reducción del tamaño de la familia y el avance de la urbanización, el Consenso de Montevideo sobre Población y Desarrollo contempla tres dimensiones importantes para la adaptación de los sistemas de protección social a las personas mayores, las pensiones, la atención básica de salud y los servicios sociales para la autonomía (CEPAL, 2019a). Ahora que nos enfrentamos a la pandemia de COVID-19, se debe continuar con las medidas de salud pública y la respuesta en cuanto a diagnóstico y tratamiento a nivel hospitalario, y también considerar el despliegue territorial del primer nivel de atención, como parte de una estrategia de atención primaria de salud (CEPAL/OPS, 2020), pero también es esencial la garantía en materia de seguridad de ingresos.

En lo que respecta a los servicios de salud, hay que tener presente que antes buscaban principalmente soluciones para ampliar el acceso frente a los costos crecientes para tratar enfermedades crónicas y degenerativas de personas cada vez mayores. Con la crisis sanitaria actual dichos costos aumentan de manera descomunal como consecuencia de una nueva enfermedad transmisible que tiene una alta letalidad en comparación con otras virosis, deja un grado aún no precisado de secuelas, exige cuidados de alto costo y afecta sobremanera a las personas mayores con enfermedades preexistentes.

Como ya se mencionó, en la medida prioritaria 26 del Consenso de Montevideo sobre Población y Desarrollo los países acordaron adecuar las acciones al nuevo perfil epidemiológico, propio de los países con estructura etaria envejecida. Si bien esto es esencial, las desigualdades a lo largo del ciclo vital se acentúan al final de la vida y, por ende, las personas mayores no constituyen un grupo homogéneo, sino que presentan distintas condiciones sociales y económicas, por lo que el acceso a la salud es diferencial. La región se caracteriza por

5 "Acordamos mejorar los sistemas de protección social para que respondan efectivamente a las necesidades de las personas mayores" (CEPAL, 2012, pág. 9).

Medida 26: "adecuar las políticas de salud a los desafíos del variado y cambiante perfil epidemiológico resultante del envejecimiento y la transición epidemiológica"; medida 31: "incluir el cuidado en los sistemas de protección social" (CEPAL, 2013, pág. 19).

Agenda 2030. La meta 1.3 de los ODS reconoce la responsabilidad general y principal del Estado de aplicar el principio de la universalidad a la protección social (Naciones Unidas, 2015)

Declaración de Asunción. "Exhortamos a los Gobiernos a tomar medidas específicas y profundizar las existentes para combatir la discriminación por edad y múltiple, el abandono, el maltrato y la violencia hacia las personas mayores, prestando especial atención a las que enfrentan situaciones de mayor riesgo y vulnerabilidad social, así como a proporcionar servicios de salud integral, cuidados, protección social y acceso a alimentos, vivienda, empleo, ocupación social y justicia, entre otros" (CEPAL, 2017, pág. 2). 
la desigualdad de acceso a la salud de las personas mayores y, al ser este servicio un derecho, en la práctica estas personas no cuentan con un acceso universal real. Con la pandemia de COVID-19 se reactiva la discusión de la adecuación del sistema de salud para brindar acceso, con amplia cobertura, no solo para atender a los enfermos crónicos sino también a aquellos que se infectan con el virus y enfrentan una muerte temprana.

En lo que respecta a la garantía de percepción de ingresos, la pandemia puede reducir significativamente los ingresos y el nivel de vida de las personas mayores. Debido a los efectos del COVID-19, la CEPAL proyecta una caída del PIB de América Latina y el Caribe en 2020 de por lo menos un 9\%, así como aumentos en los niveles de desempleo (3,4 puntos porcentuales), pobreza (7,1 puntos porcentuales, es decir unos 28,7 millones de personas más) y pobreza extrema (4,5 puntos porcentuales, es decir 15,9 millones de personas más) (CEPAL, 2020c). La recesión de la economía y otras consecuencias más amplias del COVID-19 pueden dejar a muchas personas mayores, particularmente mujeres y personas mayores con discapacidad, en situación de desventaja, con oportunidades de trabajo limitadas, y pensiones y protección social aún más inadecuadas.

En algunos estudios recientes de la CEPAL se afirma que los sistemas de pensiones de la región, que ya registraban bajos niveles de prestaciones y problemas de financiamiento, también se verán afectados por la pandemia mediante el descenso de la afiliación o cotización a dichos sistemas, especialmente en los países más expuestos al incremento del desempleo y la informalidad. Esto tendrá efectos en los ingresos por cotizaciones y en la densidad de cotizaciones en el momento del retiro, y podría conllevar la reducción de las prestaciones y una profundización de las actuales desigualdades de género (CEPAL, 2020b).

En el primer informe regional sobre la implementación del Consenso de Montevideo sobre Población y Desarrollo (CEPAL, 2019a) se afirma que la seguridad de ingresos de las personas mayores sigue siendo un asunto pendiente en todos los países. La región, por ser muy desigual económicamente y tener un porcentaje muy alto de empleos sin protección previsional, tiene una brecha enorme por resolver, con base en sistemas de pensiones no contributivas que resultan cada vez más difíciles de mantener frente a las crisis económicas y fiscales, y una fuerza de trabajo que disminuye relativamente con respecto a la población mayor.

En 2015, la cobertura efectiva de pensiones, medida por el indicador 1.3.1 de los ODS (proporción de la población cubierta por sistemas o niveles mínimos de protección social) mostraba una brecha del 30\% de población no cubierta con los mínimos necesarios entre las personas mayores de 65 años. Esta proporción de población sin cobertura ha disminuido si se compara con años anteriores, y esto se debe principalmente al aumento de las pensiones no contributivas (CEPAL, 2018 y 2019b).

Los datos más recientes disponibles para los países de la región (véase el gráfico 10) muestran que los indicadores de cobertura y suficiencia de las prestaciones de los sistemas de pensiones en la región, pese al aumento de la cobertura, las desigualdades y la desprotección, siguen siendo muy elevadas. La población económicamente activa de 15 años y más perteneciente al estrato de ingresos medio-bajos que estaba afiliada o cotizaba a un sistema de pensiones representaba el 47,5\% alrededor de 2017, en tanto que esta cobertura ascendía al 60,1\% en los estratos medio-intermedios y al 69,8\% en los estratos medio-altos (CEPAL, 2019a).

En cuanto a los montos de pensiones, las cifras más recientes son inferiores a 295 dólares en el 76,8\% de los adultos con 65 años y más que reciben pensiones contributivas (CEPAL, 2019a). Hay que tener en cuenta que en contextos de crisis económicas, como la actual, se acentúan las necesidades de recursos monetarios y, en muchas ocasiones, el ingreso de la persona mayor es el principal ingreso del hogar e incluso el único en situaciones como esta. Por tanto, en los países se han aplicado algunas medidas orientadas a brindar apoyo en este contexto. Entre ellas se destacan: i) entrega de bonos extraordinarios para los jubilados que cobran las pensiones más bajas del sistema previsional, a veces complementados con bonos de montos menores para quienes cuentan con pensiones más elevadas; ii) anticipo de los pagos de las pensiones durante un número definido de meses, y iii) retiro de fondos de las cuentas de capitalización individual (CEPAL, 2020b). 
Gráfico 10

América Latina (18 países): cotización o afiliación a sistemas de pensiones entre las personas activas de 15 años y más según estratos de ingreso per cápita, alrededor de 2017 (En porcentajes)

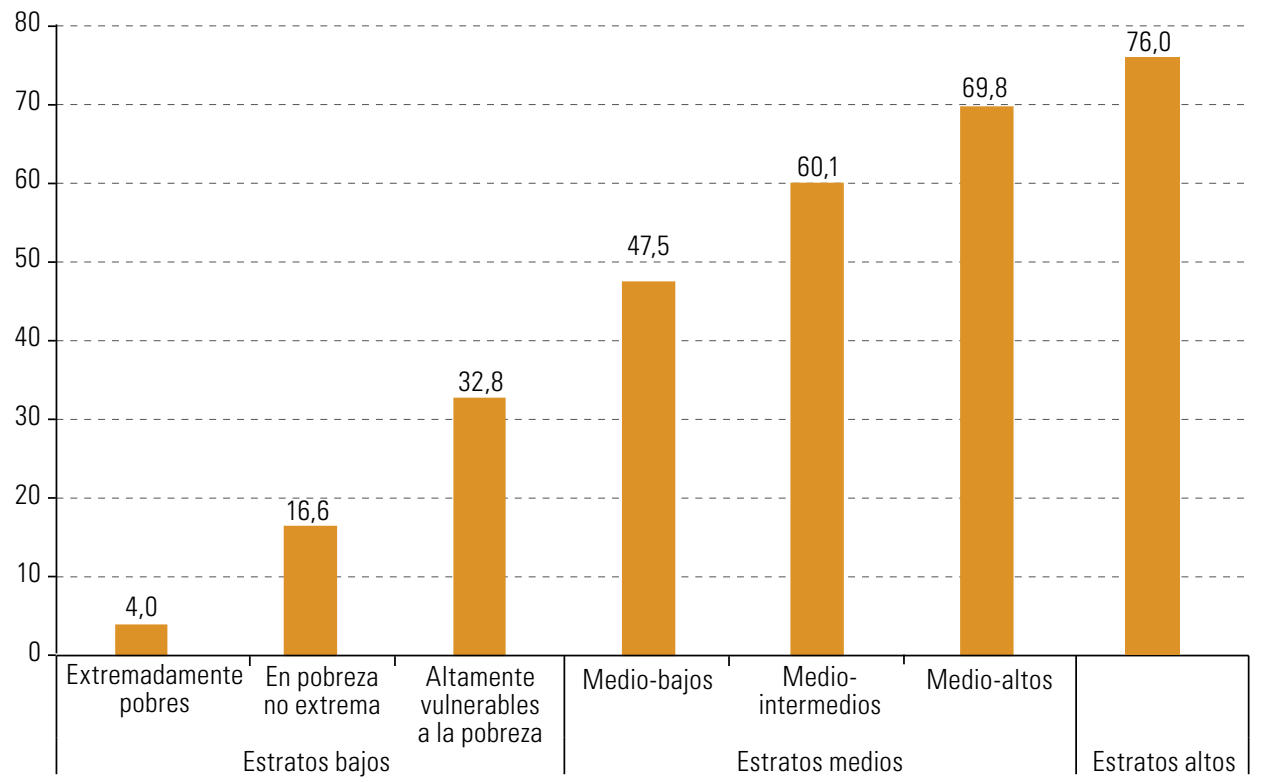

Fuente: Comisión Económica para América Latina y el Caribe (CEPAL), Panorama Social de América Latina, 2019 (LC/PUB.2019/22-P/Re v.1), Santiago, 2019.

Otro de los temas que cobra especial relevancia en la actual crisis sanitaria es el referido a los cuidados a largo plazo. Las tasas de mortalidad a causa del COVID-19 son altas entre las personas mayores de 80 años, muchas de las cuales se encuentran institucionalizadas o recibiendo cuidados en sus domicilios, no necesariamente de profesionales o personas con la capacitación adecuada. Si bien la situación en América Latina y el Caribe ha mejorado en los últimos años, principalmente en términos de legislación, las responsabilidades todavía recaen mucho sobre las familias y, en ellas, sobre las mujeres, por lo general vinculadas a la realización de tareas domésticas no remuneradas (CEPAL, 2019b).

Como ha advertido la CEPAL, la pandemia ha evidenciado de forma inédita la importancia de los cuidados para la sostenibilidad de la vida y la poca visibilidad que tiene este sector en las economías de la región, así como la excesiva carga de cuidados de las mujeres. Con anterioridad a la crisis, ellas destinaban a las actividades de trabajo y de cuidados no remunerados el triple del tiempo que dedican los hombres a las mismas tareas, y en el actual escenario, en que los sistemas sanitarios están operando al máximo de sus capacidades, mucha de la atención de salud de las personas mayores se traslada a los hogares, lo que, sin políticas de corresponsabilidad, sin duda aumenta la presión ejercida sobre el tiempo de cuidados, en particular en el caso de las mujeres (CEPAL, 2020a).

Por otra parte, en el actual contexto de crisis económica y de empleo, la Organización Internacional del Trabajo (2017, pág. xxxv) destaca que los servicios de cuidados pueden crear millones de puestos de trabajo que podrían resolver la carencia de trabajadores de salud calificados, estimada en 13,6 millones a nivel mundial. Es preciso también esforzarse para mejorar las condiciones de trabajo de muchos trabajadores de la salud y cuidados, en particular por lo que respecta a derechos laborales y al debido nivel de remuneración, a fin de transformar el trabajo no remunerado en puestos de trabajo decentes y contribuir al pleno empleo y al crecimiento inclusivo. La capacitación y la legislación adecuadas son esenciales para la protección no solo de los trabajadores sino también de las personas mayores, que muchas veces están sujetas a maltratos en los cuidados, lo que se puede ver agravado por las situaciones de confinamiento. 
En este contexto de necesidad de ampliación de los sistemas de protección y seguridad social de los servicios de salud y de cuidados, la Convención Interamericana sobre la Protección de los Derechos Humanos de las Personas Mayores facilita la estandarización de las legislaciones en la región. Es esencial que las medidas prioritarias del Consenso de Montevideo sobre Población y Desarrollo se implementen también a la luz de este instrumento, tras los problemas exacerbados por la pandemia de COVID-19.

\section{B. Acciones nacionales y locales específicas dirigidas a las personas mayores}

Desde el inicio del brote de COVID-19, incluso antes de convertirse en pandemia, la OMS ha publicado informes de situación diarios y otros documentos con datos de la vigilancia, tanto para intentar evitar la infección comunitaria como para mantenerla bajo control cuando sea inevitable, a fin de no colapsar los sistemas de salud. Para ello se ha usado el lema testear, aislar, cuidar y rastrear casos. Además de poner en práctica las recomendaciones sanitarias de la OMS, los países están implementando medidas socioeconómicas para ayudar a las poblaciones más vulnerables y a las que se quedaron sin ingresos durante las cuarentenas.

En virtud de los tipos de iniciativas implementadas por cinco países (Chile, Colombia, Guatemala, México y Perú) en relación con las acciones directamente vinculadas a la población mayor, se observan diferentes modalidades de acción. En primer lugar, hubo planes específicos dirigidos a esta población, con acciones de diversa índole, como en los casos del Perú (decreto legislativo núm. 1474 de 2020), con el objetivo de "fortalecer los mecanismos y acciones para la atención integral y protección adecuada de la persona adulta mayor que resulten necesarios durante la emergencia sanitaria ocasionada por el COVID-19" (Congreso de la República del Perú, 2020, pág. 3), y de Chile (Plan Protección Mayor), con el objetivo de "apoyar en la contención de la población mayor de 80 años que debe permanecer en sus casas por emergencia COVID-19" (SENAMA, 2020).

Otros países ejecutaron acciones, directrices o protocolos más específicos con instrucciones sanitarias y modos de actuar con las residencias de larga estadía. Algunos decretaron el aislamiento social obligatorio en los centros de larga estancia (Colombia), en tanto que otros buscaron apoyar con acciones o planes específicamente dirigidos a la contención de la población mayor en sus hogares (Chile, Colombia), o con la entrega de guías para la prevención del COVID-19 en residencias de personas mayores (México).

En el plano económico, la gran mayoría distribuyó bonos de emergencia sanitaria o entregó alimentos a la población más vulnerable, con lo que se benefició indirectamente a las personas mayores, como fue el caso de Chile, Guatemala y el Perú. Otros, como Colombia, los distribuyeron a las personas mayores.

Una importante medida sanitaria implementada en algunos países, y que indirectamente busca asegurar los derechos de las personas mayores, fue la expansión de la infraestructura hospitalaria para evitar el colapso del sistema de salud. Esta medida tuvo fuerte presencia entre las acciones de los gobiernos, siguiendo la recomendación de la OMS. Sin embargo, entre los países mencionados no se identificaron instrucciones específicas sobre la protección de dichos derechos o con el fin de evitar situaciones de discriminación contra las personas mayores en el acceso a los servicios de salud, precisamente en momentos de recursos escasos como los que conlleva la crisis sanitaria.

Las acciones son variadas y se aplican en diferentes momentos, con mucha o poca interacción entre distintos sectores gubernamentales. En el caso de la población mayor, hay países con acciones muy dirigidas y claras, con actuación de sectores relacionados con las políticas para este sector poblacional. En otros países esta población se incluyó entre las poblaciones vulnerables. En cuanto a las medidas sanitarias de cuidados e higiene, las instrucciones de la OMS fueron divulgadas en los países, pero no siempre la sociedad civil y los gobiernos reaccionaron a tiempo frente a la gravedad de la pandemia, lo que afectó la adecuada implementación de las instrucciones y recomendaciones de dicho organismo. En el recuadro 4 se presenta una sistematización de algunas de estas acciones y medidas en los países de América Latina y el Caribe. 
Recuadro 4

Algunas medidas para proteger a las personas mayores del COVID-19 en los países de la región

- Chile: Se implementó el Plan Protección Mayor, que cuenta con un conjunto de medidas que buscan reforzar el cuidado de las personas mayores de 80 años y más que deben permanecer en su casa como medida de protección contra el coronavirus. Se pusieron en marcha algunas acciones específicas, como la entrega de cajas de alimentos a la población más afectada por el brote de COVID-19 en el marco del programa Alimentos para Chile. Desde el punto de vista sanitario, los sistemas hospitalarios - público y privado - funcionaron en red para atender a los enfermos de COVID-19, medida que es de utilidad para toda la población, pero principalmente para las personas mayores, que son las más afectadas. Se crearon residencias sanitarias para las personas enfermas con síntomas leves que necesitaban estar aisladas, donde se ofrecían servicios de cuidados básicos y alimentación, principalmente a aquellas personas que viven solas o con población de alto riesgo. Se implementaron planes económicos como el ingreso familiar de emergencia y el Congreso aprobó el retiro del 10\% de los fondos acumulados de pensiones.

- Colombia: Los servicios para las personas mayores de 70 años y más fueron decretados servicios esenciales. Se realizaron pagos adicionales a los beneficiarios del Programa Colombia Mayor y se implementaron medidas para proteger los derechos de los pensionados y los beneficiarios tanto del Servicio Social Complementario de Beneficios Económicos Periódicos (BEPS) como del Programa de Subsidio al Aporte en Pensión. Se decretó el aislamiento preventivo de personas mayores en centros de larga estancia y el cierre parcial de actividades en los centros vida y los centros día, donde las personas mayores solo podían salir en situaciones excepcionales. El Ministerio de Salud brindó orientaciones específicas para la prevención, contención y mitigación del coronavirus en hogares con presencia de personas mayores, los centros vida, los centros día y los centros de protección de larga estancia. Para proteger y dar apoyo a las personas mayores ante el cierre de los centros vida y los centros día, la Unidad Nacional para la Gestión del Riesgo de Desastres (UNGRD) determinó una directriz que incluyó la solicitación a los gobiernos locales de que entregaran alimentación en el domicilio a las personas mayores más vulnerables.

- Costa Rica: Se ha puesto especial énfasis en las personas mayores. El Consejo Nacional de la Persona Adulta Mayor (CONAPAM) está implementando una campaña de prevención de la violencia contra las personas mayores y el respeto de sus derechos humanos, incluidos los cuidados. En los hogares de larga estancia se puso en marcha un plan para la prevención y atención de casos de COVID-19 en las personas residentes y se aprobó la ampliación de la red de cuidado para atender a más de 14.800 beneficiarios de edad avanzada en su domicilio.

- Cuba: el Ministerio de Salud Pública mantiene estrictas medidas de prevención para proteger la vida de las personas mayores. Al igual que con el resto de la población, se están aplicando estrategias basadas en la investigación activa, la clasificación de los casos, el seguimiento a los contactos, el tratamiento especial de los grupos vulnerables y el seguimiento a las altas de los casos confirmados. Las casas de abuelos están adscritas a un hospital para recibir la atención que este brinde y en cada uno de ellos hay un consultorio con un médico y enfermera de familia. Asimismo, cuentan con personal de trabajo social que ha sido capacitado para rastrear problemas respiratorios y ante el primer síntoma proceder según lo establecido en el protocolo de atención. En los hogares de ancianos se cuenta con personal médico y de enfermería. Se recoge información periódica de las casas de abuelos y los hogares de ancianos para conocer la incidencia de casos de infección respiratoria y se cuenta con salas de aislamiento en dichos centros. Además, las personas que asisten diariamente a centros de cuidados reciben la alimentación en el domicilio para evitar el riesgo de contagio.

- El Salvador: Se puso en marcha el Plan de Respuesta y Alivio Económico ante la Emergencia Nacional contra el COVID-19, que contempla distintas medidas económicas y sociales para mitigar las consecuencias de la propagación del COVID-19. Entre las medidas para personas mayores se estableció que el sector público y la empresa privada envíen a casa, sin excepción, a sus trabajadores mayores de 60 años y más sin perder su remuneración y, cuando sea posible, se facilite el teletrabajo.

- Guatemala: El Ministerio de Salud Pública y Asistencia Social (MSPAS) informó a la población de ciertas normas, entre las que se destaca que el sector patronal debe considerar dejar que las personas de 70 años y más o con enfermedades graves que puedan realizar trabajo remoto, el cierre de los centros de recreación laboral, y el control o la restricción de visitas en asilos o casas de reposo para personas mayores. También se puso en marcha el Programa de Apoyo Alimentario y Prevención del COVID-19. Entre las medidas económicas, dirigidas a la población más vulnerable, se encuentra la Ley de Rescate Económico a las Familias por los Efectos Causados por el COVID-19. El Poder Ejecutivo y el Ministerio de la Defensa Nacional repartieron 200.000 cajas de víveres (Juntos Saldremos Adelante) aportadas por la iniciativa privada.

- México: Se adelantó el pago de las pensiones del Programa para el Bienestar de las Personas Adultas Mayores, que entregará un total de 212,55 dólares por persona, equivalente a los montos de los bimestres marzo-abril y mayo-junio. El Gobierno de México ha puesto a disposición de la población un sitio web con información esencial sobre el COVID-19 (Gobierno de México, 2020b).

- Panamá: La Caja de Seguro Social entregó fármacos, lo que beneficia principalmente a las personas de 65 años y más que padezcan una enfermedad crónica, y el personal autorizado realiza visitas domiciliarias a personas mayores. Se están georreferenciando los albergues y hogares para detectar a la población mayor que reside en instituciones de cuidados de largo plazo.

- República Dominicana: El Gobierno ha declarado a las personas mayores de prioridad absoluta. Para ello, se garantizan las pruebas diagnósticas de COVID-19 para personas de 59 años y más, se otorga una transferencia monetaria adicional, equivalente a 120 dólares, a los hogares donde viva una persona mayor y se brinda alimentación a domicilio y suministros de 
protección para las personas mayores que asisten a los centros de cuidado. También se promueve la corresponsabilidad en la atención de las personas mayores por medio de la participación de jóvenes voluntarios que asisten a estas personas en sus domicilios para la entrega de alimentos.

- Perú: Se dictaron medidas de prevención y control del COVID-19 mediante un Plan de Acción amplio, y se creó la Comisión Multisectorial de Alto Nivel para conducir las labores de coordinación y articulación orientadas a la prevención, protección y control del COVID-19. Se dictó el decreto legislativo núm. 1474, que tiene por finalidad garantizar la prevención, atención y protección de las personas mayores durante la emergencia sanitaria e incluye una serie de medidas, especificando los deberes del Estado y de varios sectores para proteger a este grupo poblacional, así como para proteger los derechos de las personas mayores en sus hogares y en residencias de larga estancia. Con el Plan de Acción para la implementación de la Red de Soporte para la Persona Adulta Mayor con Alto Riesgo y la Persona con Discapacidad Severa frente al COVID-19 se identificó y georreferenció a este grupo poblacional para la entrega de paquetes de servicios y el seguimiento nominal del grupo identificado durante la pandemia. En el área económica, se instauró un decreto de urgencia para transferencias monetarias a las personas en riesgo. Además, la Red de Soporte brinda, entre otras cosas, información de higiene sanitaria, ayuda para la identificación de signos y alarmas de infección, e inmunización contra la influenza.

Fuente: Comisión Económica para América Latina y el Caribe (CEPAL), Observatorio COVID-19 en América Latina y el Caribe [en línea] https:// www.cepal.org/es/temas/covid-19; S. Huenchuan, "El derecho a la vida y la salud de las personas mayores en el marco de la pandemia por COVID-19" (LC/MEX/TS.2020/9), Ciudad de México, Comisión Económica para América Latina y el Caribe (CEPAL), 2020; Gobierno de México, "Adultos mayores", 2020 [en línea] https://coronavirus.gob.mx/adultos-mayores/.

Por último, es importante reconocer que las medidas adoptadas, además de tener en cuenta las recomendaciones de la OMS, debieron adecuarse a los contextos locales. Por ello, la coordinación entre las acciones puestas en marcha por los Estados, en todos los niveles de administración, por la sociedad civil y por la sociedad civil organizada, con inclusión, principalmente, de los especialistas en el área de la salud, ha dictado la evolución de la pandemia en los distintos países.

\section{Recomendaciones para la orientación de políticas}

Los países de América Latina y el Caribe han respondido de distinta manera a la hora de enfrentar la pandemia de COVID-19. Con diferentes niveles de infectados y mortalidad, aún son presa de grandes incertidumbres sobre la magnitud de la pandemia, así como de sus consecuencias económicas, sociales y psicológicas. Esta pandemia ha traído desafíos sin precedentes a la humanidad y presenta una amenaza desproporcionada para la salud, la vida, los derechos y el bienestar de las personas mayores. La recuperación del COVID-19 es una oportunidad para construir una sociedad más inclusiva, equitativa y amigable, que fomente el envejecimiento saludable y los derechos humanos y la dignidad de las personas mayores. En este sentido, se pueden enumerar algunas recomendaciones específicas que resultan del panorama trazado en este documento:

1. Los instrumentos acordados a nivel internacional, ampliamente discutidos y en proceso de implementación, como el Plan de Acción Internacional de Madrid sobre el Envejecimiento, la Carta de San José sobre los Derechos de las Personas Mayores de América Latina y el Caribe, la Convención Interamericana sobre la Protección de los Derechos Humanos de las Personas Mayores, el Consenso de Montevideo sobre Población y Desarrollo, la Agenda 2030 para el Desarrollo Sostenible y la Declaración de Asunción, son herramientas de referencia para la priorización de medidas que busquen asegurar que la pandemia cause el menor impacto posible y que se garanticen los derechos de las personas mayores y de la población en general.

2. Las tendencias del proceso de envejecimiento poblacional ganan relevancia en un escenario de pandemia donde las personas mayores tienen un riesgo significativamente más elevado de enfermedad grave y mortalidad por COVID-19. Esto implica que los países necesitan orientar sus políticas de manera directa y explícita a la protección de las personas mayores, garantizando, en primer lugar, la protección para evitar el contagio y, cuando ya hay infección, el acceso a tratamientos adecuados, sin discriminación de ningún tipo. Además, deben implementar acciones que garanticen el tratamiento de 
la enfermedad por coronavirus y sus consecuencias, y poner en marcha planes para organizar programas de inmunización mediante vacunas para las personas mayores, garantizando que se dé prioridad a las más vulnerables.

3. Es necesario orientar las políticas reconociendo que "las personas mayores, en razón de su edad y su condición de vulnerabilidad, continúan siendo discriminadas y son víctimas de abusos y maltratos, lo que por ende afecta el goce y ejercicio de sus derechos" (CEPAL, 2013, pág. 17). Por lo tanto, las instituciones de larga estadía necesitan el apoyo de las políticas públicas para la capacitación y calificación de recursos humanos, así como para obtención de recursos financieros, a fin de garantizar la mejor atención en todo momento, pero especialmente en tiempos de crisis de salud como la del COVID-19.

4. Una implicación de política directa que deriva de la información vinculada a la corresidencia intergeneracional es la necesidad de disminuir el riesgo de contagio. Para ello, el cierre de las escuelas y el confinamiento del conjunto del hogar son las opciones más efectivas, aunque difícilmente sostenibles por largo tiempo y con evidentes costos colaterales. Desde luego que hay otras opciones, pero estas resultan más difíciles de implementar (como ocurre con el aislamiento de las personas mayores dentro del hogar). Sin embargo, hay soluciones complementarias, como las residencias sanitarias. Y, ciertamente, la adopción de medidas higiénicas estrictas de prevención a escala del hogar (lavado de manos, uso de mascarillas, mantenimiento de distancia física, uso regular de desinfectantes en superficies y otras) también podría servir, pero hay muy poca evidencia sobre el seguimiento efectivo de tales medidas en los hogares.

5. Se necesitan acciones sociales para garantizar que las personas que viven solas y en aislamiento social en momentos de pandemia tengan un seguimiento adecuado y dispongan de información para la búsqueda de ayuda en caso de que necesiten obtener bienes materiales y medicinas, así como apoyo emocional. Para ello, es esencial mantener registros administrativos donde se identifiquen los hogares con personas mayores que viven solas y los datos de sus contactos en caso de emergencia.

6. Debido a las fragilidades resultantes de la vejez, no solo durante la pandemia, las personas mayores necesitan poder tener acceso al agua y al saneamiento para protegerse de las enfermedades transmisibles. Tanto en las áreas rurales como en las urbanas segregadas y en condiciones de pobreza, que tienen servicios inadecuados de agua y saneamiento, son necesarias acciones específicas para garantizar el suministro continuo y adecuado de estos servicios a corto, mediano y largo plazo.

7. En vista del envejecimiento de la población y del cambio en el perfil epidemiológico, con un aumento de las enfermedades crónico-degenerativas, el sistema de salud debe organizarse para brindar la mejor atención primaria de la salud y estar preparado, a su vez, para un momento como el actual, de forma de poder ofrecer la atención sanitaria necesaria a la población de edad avanzada dentro de su rutina.

8. En cuanto a la protección social, la región presenta grandes rezagos históricos que no se resolverán a corto plazo. En momentos de crisis sanitaria con crisis económica agravada, es necesario garantizar que los recursos de las pensiones lleguen a la población mayor, principalmente a las personas más vulnerables, que son las que todavía no están cubiertas y las que reciben pensiones no contributivas. Es necesario dar la mayor prioridad política a las acciones urgentes de identificación y localización de las personas vulnerables, así como a la definición de los mecanismos de distribución.

9. Debido a las cuestiones históricas de falta de protección social, la segregación femenina en el mercado de trabajo no remunerado y su mayor vinculación con los cuidados, sumado a la mayor esperanza de vida de las mujeres, todas las políticas y acciones deben tener necesariamente presentes las inequidades de género. Al respecto, uno de los desafíos más importantes que tiene la región es la reorganización social de los cuidados para alcanzar la plena corresponsabilidad entre el Estado, el mercado y las familias.

Por último, pero no menos importante, en todos los temas tratados queda claro que existe un importante déficit de datos e información para lograr mejores diagnósticos y análisis. La crisis ha puesto en evidencia una vez más la gran necesidad de contar con sistemas robustos de recolección y difusión de datos, con desgloses a nivel subnacional por edad, sexo y causa de muerte. Por lo tanto, se necesitan políticas y un financiamiento adecuado para elaborar y mejorar los indicadores destinados a monitorear tanto la evolución epidemiológica de la pandemia como los datos socioeconómicos y demográficos, que son esenciales para la identificación de los grupos más vulnerables y los factores de riesgo. 


\section{Bibliografía}

ACNUDH (Oficina del Alto Comisionado de las Naciones Unidas para los Derechos Humanos) (2020), "COVID-19 and the rights of persons with disabilities: guidance", Ginebra, 29 de abril [en línea] https://www.ohchr.org/Documents/Issues/Disability/ COVID-19_and_The_Rights_of_Persons_with_Disabilities.pdf.

Arenas de Mesa, A. (2019), Los sistemas de pensiones en la encrucijada: desafíos para la sostenibilidad en América Latina, Libros de la CEPAL, N 159 (LC/PUB.2019/19-P), Santiago, Comisión Económica para América Latina y el Caribe (CEPAL).

Balbo, N., F. Billari y A. Melegaro (2020), "The strength of family ties and COVID-19", Contexts, Washington, D.C., Asociación Estadounidense de Sociología, 6 de abril [en línea] https://contexts.org/blog/structural-shocks-and-extreme-exposures/\#balbo.

BID (Banco Interamericano de Desarrollo) (2020a), "COVID-19 y adultos mayores" [en línea] https://www.iadb.org/es/panorama/covid-19-y-adultos-mayores. (2020b), "Indicadores: panorama de envejecimiento y atención a la dependencia" [en línea] https://www.iadb.org/es/panorama/indicadores.

Brasil, Gobierno de (2020), "Open DataSUS" [base de datos en línea] https://opendatasus. saude.gov.br/

CDC (Centro para el Control y la Prevención de Enfermedades) (2020), "Personas con discapacidad", 11 de septiembre [en línea] https://espanol.cdc.gov/coronavirus/2019ncov/need-extra-precautions/people-with-disabilities.html.

Centro para el Control y la Prevención de Enfermedades de China (2020), "Vital surveillances: the epidemiological characteristics of an outbreak of 2019 novel coronavirus diseases (COVID-19)-China 2020", China CDC Weekly, vol. 2, No 8, Beijing.

CEPAL (Comisión Económica para América Latina y el Caribe) (2020a), "La pandemia del COVID-19 profundiza la crisis de los cuidados en América Latina y el Caribe", Informes COVID-19, Santiago, abril.

(2020b), "El desafío social en tiempos del COVID-19", Informe Especial COVID-19, No 3, Santiago, mayo.

(2020c), "Dimensionar los efectos del COVID-19 para pensar en la reactivación", Informe Especial COVID-19, No 2, Santiago, abril.

(2019a), Primer informe regional sobre la implementación del Consenso de Montevideo sobre Población y Desarrollo (LC/CRPD.3/6), Santiago.

(2019b), Panorama Social de América Latina, 2019 (LC/PUB.2019/22-P/Rev.1), Santiago (2018), Panorama Social de América Latina, 2017 (LC/PUB.2018/1-P), Santiago. (2017), Declaración de Asunción: Construyendo sociedades inclusivas: envejecimiento con dignidad y derechos, Santiago.

(2013), Consenso de Montevideo sobre Población y Desarrollo (LC/L.3697), Santiago. (2012), Carta de San José sobre los Derechos de las Personas Mayores de América Latina y el Caribe (LC/G.2537), Santiago.

CEPAL/OPS (Comisión Económica para América Latina y el Caribe/Organización Panamericana de la Salud) (2020), "Salud y economía: una convergencia necesaria para enfrentar el COVID-19 y retomar la senda hacia el desarrollo sostenible en América Latina y el Caribe", Informes COVID-19, Santiago.

Chile, Gobierno de (2020), "Cifras oficiales COVID-19" [base de datos en línea] https:// www.gob.cl/coronavirus/cifrasoficiales.

CIDH (Comisión Interamericana de Derechos Humanos) (2020), "La CIDH urge a los Estados a garantizar los derechos de las personas mayores frente a la pandemia del COVID-19", Comunicado de Prensa, Washington, D.C., 23 de abril [en línea] https:// www.oas.org/es/cidh/prensa/comunicados/2020/088.asp.

Cisternas, M. y V. Pineda (2020), "Declaración conjunta: gobiernos locales y personas con discapacidad en relación al COVID-19", Nueva York, Naciones Unidas, 5 de mayo [en línea] https://www.un.org/development/desa/disabilities/wp-content/uploads/ sites/15/2020/05/Decl-Gobiernos-locales-y-pcd-Covid-19-5mayo-F.pdf.

Comas-Herrera, A. y otros (2020), "Mortality associated with COVID-19 outbreaks in care homes: early international evidence", Londres, International Long-Term Care Policy Network, 3 de mayo [en línea] https://ltccovid.org/wp-content/uploads/2020/05/ Mortality-associated-with-COVID-3-May-final-7.pdf.

Congreso de la República del Perú (2020), "Decreto legislativo No 1474", El Peruano, Lima, 2 de mayo. 
Dowd, J. y otros (2020), "Demographic science aids in understanding the spread and fatality rates of COVID-19", Proceedings of the National Academy of Sciences (PNAS), vol. 117, No 18, Washington, D.C., Academia de Ciencias de los Estados Unidos

Esteve, A., I. Permanyer y D. Boertien (2020), "La vulnerabilidad de las provincias españolas a la COVID-19 según su estructura por edad y de co-residencia: implicaciones para el (des)confinamiento", Perspectives démografiques, No 19, Barcelona, Centro de Estudios Demográficos (CED)

González, D. y M. Stang (2014), "Las personas con discapacidad en América Latina a 20 años de los consensos de El Cairo: la necesidad de información para políticas y programas", Notas de Población, No 99 (LC/G.2628-P), Santiago, Comisión Económica para América Latina y el Caribe (CEPAL)

Guilmoto, C. (2020), "COVID-19 death rates by age and sex and the resulting mortality vulnerability of countries and regions in the world", mayo [en línea] https://www. medrxiv.org/content/10.1101/2020.05.17.20097410v1.

Huenchuan, S. (2020a), COVID-19: recomendaciones generales para la atención a personas mayores desde una perspectiva de derechos humanos (LC/MEX/TS.2020/6/Rev.1), Ciudad de México, Comisión Económica para América Latina y el Caribe (CEPAL) (2020b), "El derecho a la vida y la salud de las personas mayores en el marco de la pandemia por COVID-19" (LC/MEX/TS.2020/9), Ciudad de México, Comisión Económica para América Latina y el Caribe (CEPAL).

(ed.) (2018), "Envejecimiento, personas mayores y Agenda 2030 para el Desarrollo Sostenible: perspectiva regional y de derechos humanos", Libros de la CEPAL, NN 154 (LC/PUB.2018/24-P), Santiago, Comisión Económica para América Latina y el Caribe (CEPAL).

Lloyd-Sherlock, E. y otros (2020), "Bearing the brunt of COVID-19: older people in low and middle income countries", BMJ, vol. 368, Londres, BMJ Publishing Group, marzo.

México, Gobierno de (2020a), "COVID-19 México" [base de datos en línea] https:// coronavirus.gob. $\mathrm{mx} /$ datos/.

(2020b), "Adultos mayores" [en línea] https://coronavirus.gob.mx/adultos-mayores/.

Naciones Unidas (2020a), Progresos realizados para lograr los Objetivos de Desarrollo Sostenible: Informe del Secretario General (E/2020/57), Nueva York, abril. (2020b), Policy Brief: The Impact of COVID-19 on Older Persons, Nueva York, mayo (2019a), World Population Prospects 2019 [base de datos en línea] https://population. un.org/wpp/Download/Standard/Population/

(2019b), World Population Prospects 2019: Highlights (ST/ESA/SER.A/423), Nueva York. (2019c), Database on the Households and Living Arrangements of Older Persons 2019 [en línea] https://population.un.org/LivingArrangements/index.html.

(2019d), "Living arrangements of older persons around the world", Population Facts, No 2019/2, Nueva York, abril.

(2015), Transformar nuestro mundo: la Agenda 2030 para el Desarrollo Sostenible (A/RES/70/1), Nueva York.

(2003), Declaración Política y Plan de Acción Internacional de Madrid sobre el Envejecimiento, Nueva York.

Nepomuceno, M. y otros (2020), "Besides population age structure, health and other demographic factors can contribute to understanding the COVID-19 burden", Proceedings of the National Academy of Sciences (PNAS), vol. 117, No 25, Washington, D.C., Academia de Ciencias de los Estados Unidos.

OEA (Organización de los Estados Americanos) (2015), Convención Interamericana sobre la Protección de los Derechos Humanos de las Personas Mayores, Washington, D.C.

OIT (Organización Internacional del Trabajo) (2017), Informe Mundial sobre la Protección Social 2017-19: La protección social universal para alcanzar los Objetivos de Desarrollo Sostenible, Ginebra.

OMS (Organización Mundial de la Salud) (2020a), Actualización de la estrategia frente a la COVID-19, Ginebra, 14 de abril [en línea] https://www.who.int/docs/defaultsource/coronaviruse/covid-strategy-update-14april2020_es.pdf.

(2020b), "Mental health and psychosocial considerations during the COVID-19 outbreak", Ginebra, 18 de marzo [en línea] https://www.who.int/docs/defaultsource/coronaviruse/mental-health-considerations.pdf. (2020c), "Infection prevention and control guidance for long-term care facilities in the context of COVID-19: interim guidance", Ginebra, 21 de marzo [en línea] https://apps.who.int/iris/bitstream/handle/10665/331508/WHO-2019-nCoVIPC_long_term_care-2020.1-eng.pdf. 
(2020d), "Agua, saneamiento, higiene y gestión de desechos en relación con el SARS-CoV-2, el virus causante de la COVID-19: orientaciones provisionales", Ginebra, 29 de julio [en línea] https://www.who.int/es/publications/i/item/WHO2019-nCoV-IPC-WASH-2020.4

(2020e), Fortalecimiento de la preparación para la COVID-19 en las ciudades y otros entornos urbanos: orientaciones provisionales para las autoridades locales, Ginebra. (2020f), Consideraciones relativas a la discapacidad durante el brote de COVID-19, Ginebra.

(2020g), "Information note: COVID-19 and NCDs", Ginebra [en línea] https://www. who.int/publications/m/item/covid-19-and-ncds.

(2015), Informe mundial sobre el envejecimiento y la salud, Ginebra.

OPS (Organización Panamericana de la Salud) (2020), COVID-19 Information System for the Region of the Americas [base de datos en línea] https://paho-covid19-responsewho.hub.arcgis.com/.

Promislow, D. (2020), "A geroscience perspective on COVID-19 mortality", The Journals of Gerontology, vol. 75, No 9, Oxford, Oxford University Press.

Ritchie, H. y otros (2020), "Coronavirus (COVID-19) Testing", Oxford, Universidad de Oxford, octubre [base de datos en línea] https://ourworldindata.org/coronavirus-testing.

Rodríguez, J. y M. Cobos (2014), "Fecundidad adolescente, unión y crianza: un nuevo escenario en América Latina", Revista Latinoamericana de Población, vol. 8, No 15, Buenos Aires, Asociación Latinoamericana de Población (ALAP).

Ruggles, S. y otros (2017), "Integrated Public Use Microdata Series: Version 7.0 [dataset]", Minneapolis, Universidad de Minnesota [en línea] https://ipums.org/projects/ ipums-usa/d010.v7.0

SENAMA (Servicio Nacional del Adulto Mayor) (2020), "Primera dama y ministro Sichel anuncian "Protección Mayor" que promueve el cuidado y contención de personas mayores", Santiago, 25 de mayo [en línea] http://www.senama.gob.cl/noticias/ primera-dama-y-ministro-sichel-anuncian-proteccion-mayor-que-promueve-elcuidado-y-contencion-de-per.

Tableau Public (2018), "Condiciones de salud de la población adulta mayor" [base de datos en línea] https://public.tableau.com/profile/observatorio.envejecimiento\#!/ vizhome/g_salud/dsh_salud.

Ullmann, H., C. Maldonado y M. Nieves (2014), "Families in Latin America: changes, poverty, and access to social protection", International Journal of Sociology of the Family, vol. 40, No 2, Tacoma, International Journals.

UNFPA (Fondo de Población de las Naciones Unidas) (2020), "Implications of COVID-19 for older persons: responding to the pandemic", UNFPA Global Technical Brief, Nueva York, abril.

Este documento forma parte de un conjunto de informes elaborados por la Comisión Económica para América Latina y el Caribe (CEPAL) sobre la evolución y los efectos de la pandemia de COVID-19 en la región. Fue elaborado por el Centro Latinoamericano y Caribeño de Demografía (CELADE)-División de Población de la CEPAL, dirigido por Paulo Saad, bajo la coordinación general de Alicia Bárcena, Secretaria Ejecutiva de la CEPAL.

La publicación de este documento se realiza gracias a la cooperación del Gobierno de Alemania a través del Ministerio Federal de Cooperación Económica y Desarrollo (BMZ) y de la Deutsche Gesellschaft für Internationale Zusammenarbeit (GIZ).

Los límites y los nombres que figuran en los mapas incluidos en este documento no implican su apoyo o aceptación oficial por las Naciones Unidas.

Copyright () Naciones Unidas, 2020 